\title{
الموقع الجغرافي للعالم السفلي (كور / حيجال) ونظامه في الفكر العراقي القديم من خلال المصادر النصية
}

د.دينا إبر اهيم سليمان

مدرس آثار مصر والثرق الأدنى القديم

\section{مقدمة}

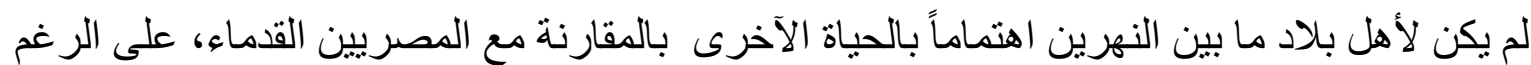

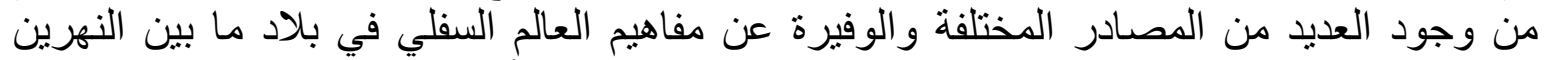

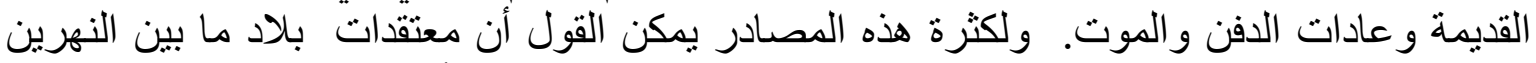

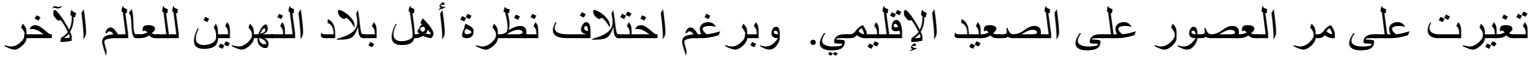

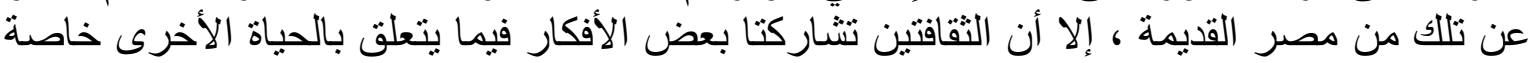

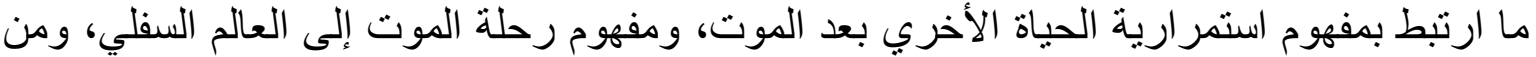

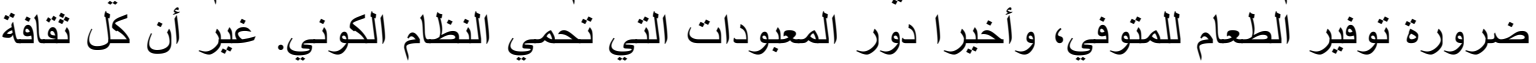
متميزة في مفاهيمها للعالم السفلي نفسه وفئ ولكل ثقافة خصائص مختلفة في الأفكار المشتركة بينهما.

ولعل من بين أهم المصادر النصية من بلاد ما بين النهرين الجديرة بالاهتمام التي تتعلق بمفاهيم العالم

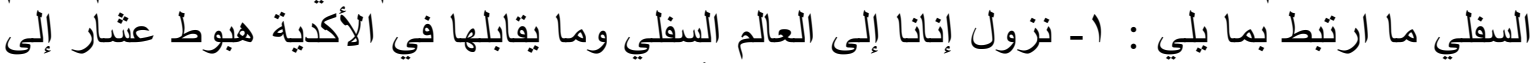

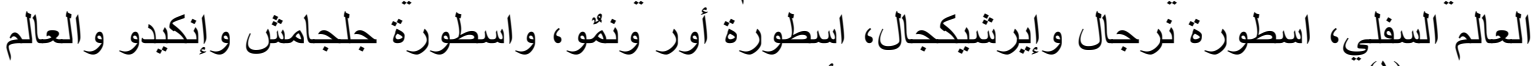

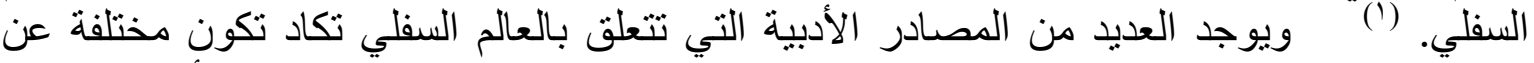

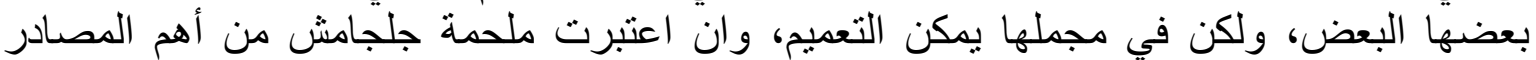

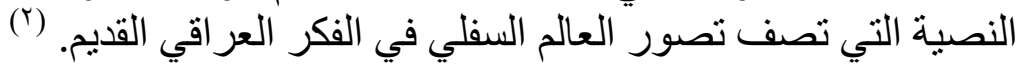

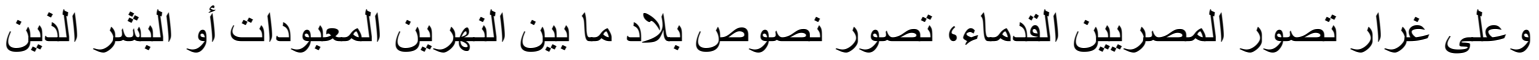

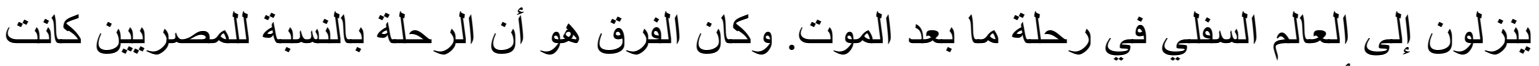

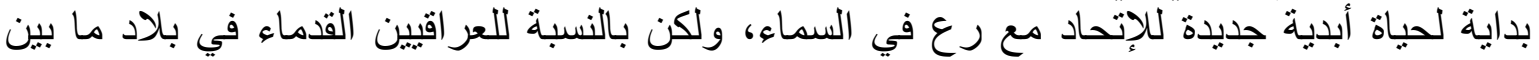

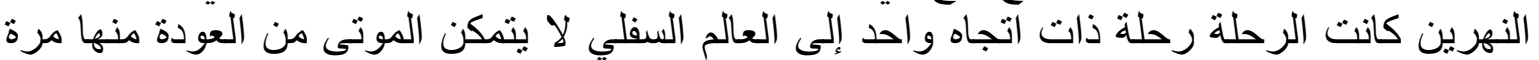

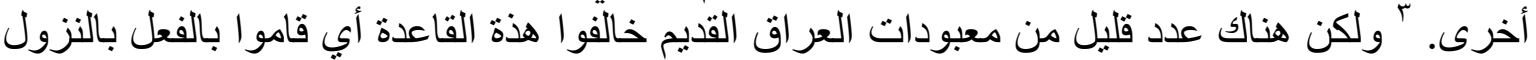

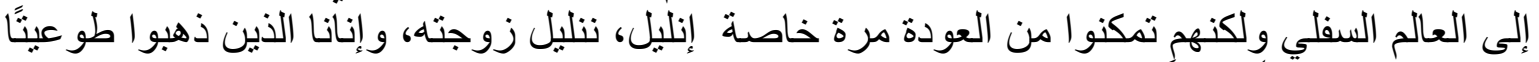

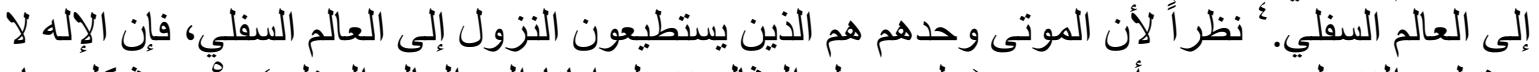

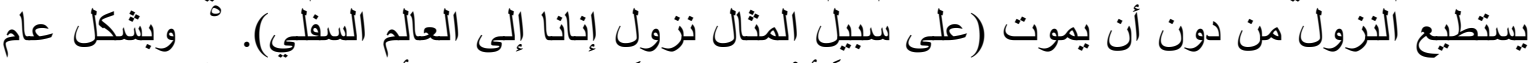

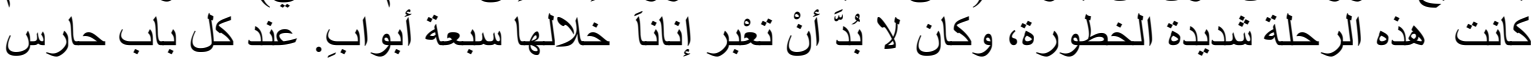
البو ابة.

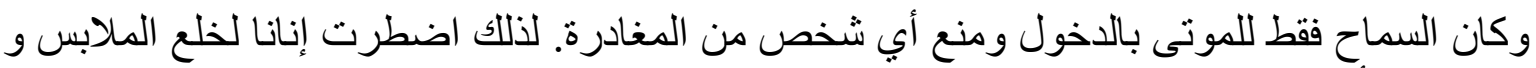

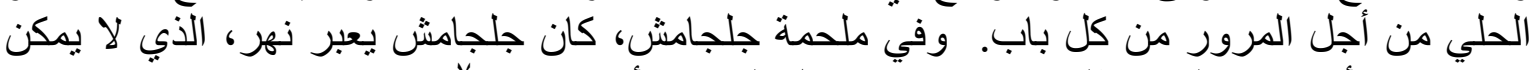

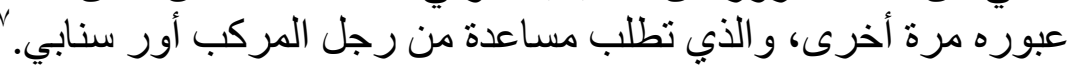

وبإعتبار السماء حكراً على المعبودات التي لا يستطيع الموتى الدخول إلبها، فإنها كانت عكس العالم

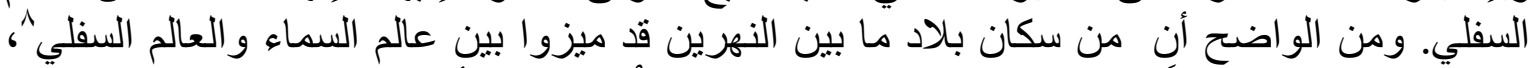

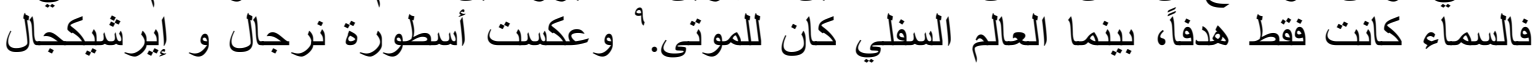


سلالم تربط ما بين العالم السفلي و السماء".' كما أن السومريين قد ميزوا بوضوح عين مملكة الموتى ومملكة الأحياء.

و على الرغم من أن النصوص و المصادر السومرية لا تقدم إجابة مباشرة على الجانب الجغر افي للعالم السفلي ، فإن المفاهيم العامة المتعلقة بموقعه الجغر افي (موضوع البودم البحث) ملحوظة.

يستهدف هذا البحث جوانب من الفكر العر اقي القديم وتصوره عن الموقع الجغر افي للعالم السفلي :

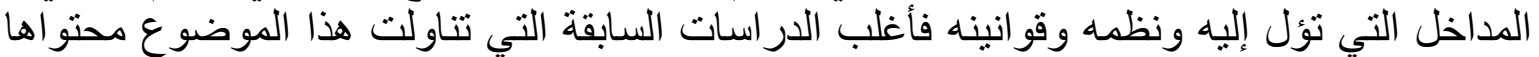

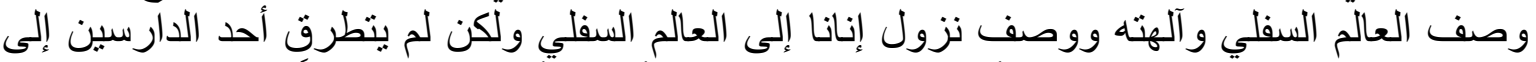

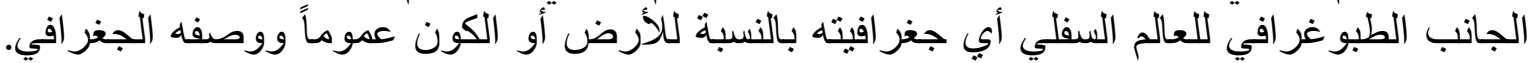

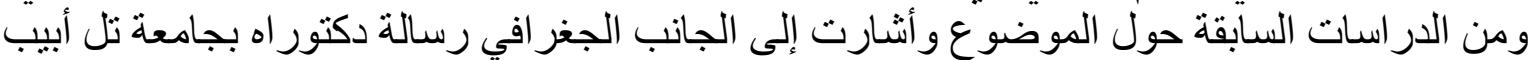

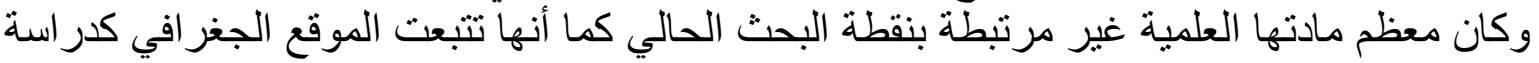

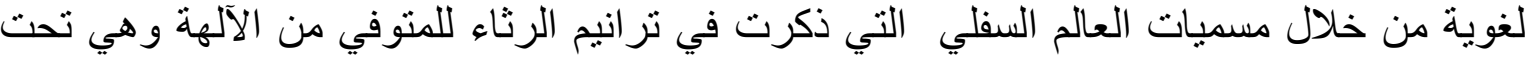

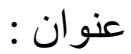

Katz, Dina, The Image of the Netherworld in the Sumerian Sources.

Bethseda, Tel Aviv University,1993.

تعريف العالم السفلي وأغراضه في الفكر السومري القديم

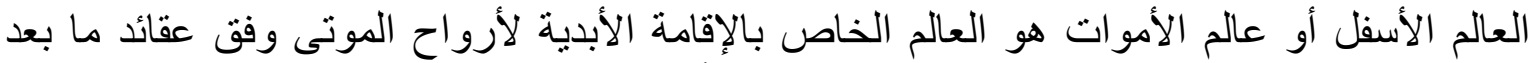

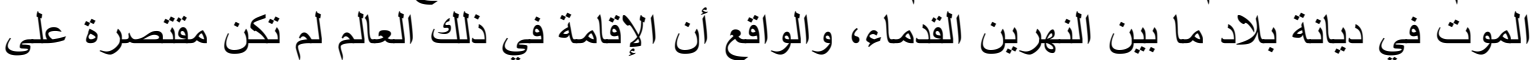

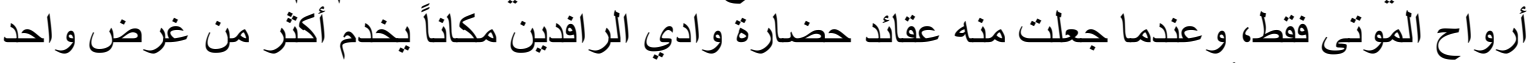
بالإضافة إلى إقامة أرواح المونى إنى، يمكن إجمالها فيما يلي:

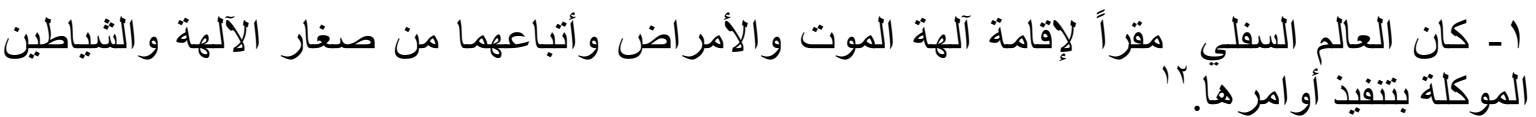
بـ اعتبر العالم الأسفل مكاناً تقيم فيه بعض المعبودات التي ذكر موتها في الاساطير الدينية إضافة

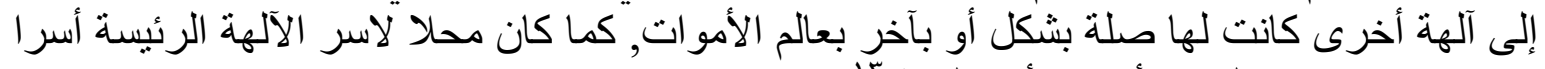

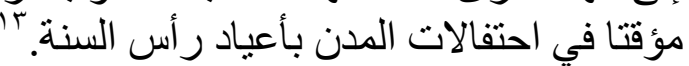

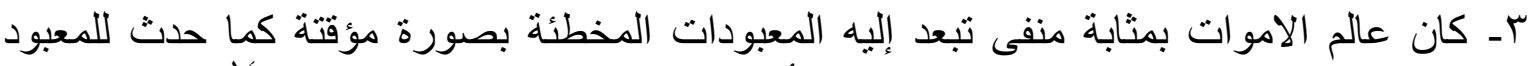

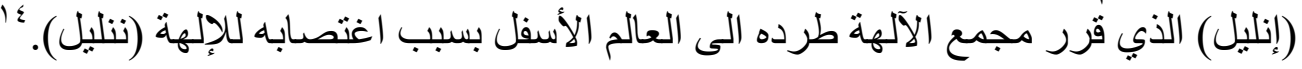

عـ كان ينظر إلى العالم الأسفل على أنه مصدر تأني منه الثياطيين المؤذية والأشباح أو الأرواح

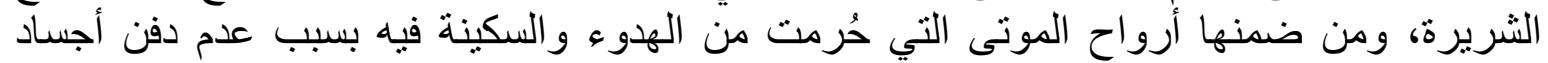

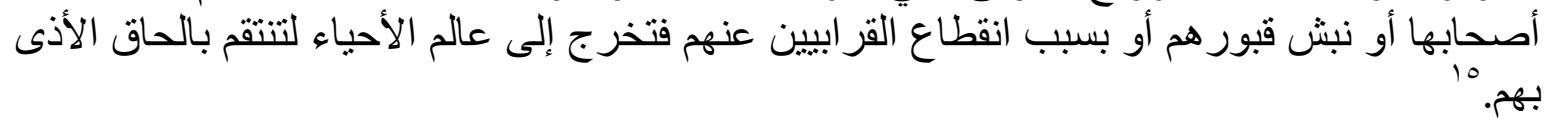

وكل هذه الوظائف التي تخص العالم السفلي تتم عن الأهمية التي حازها في العقائد الدينية لحضارة

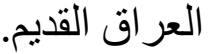




\section{أسماء العالم السفلي:}

تضمنت المصادر النصية من الحضارة العر اقية القديمة عدة أسماء للعالم السفلي أثهر ها: القبر "قبرو" Qabru: وهي كلمة أكدية مشابهة لكلمة قبر العربية، وقد استخدمت للالالة على العالم

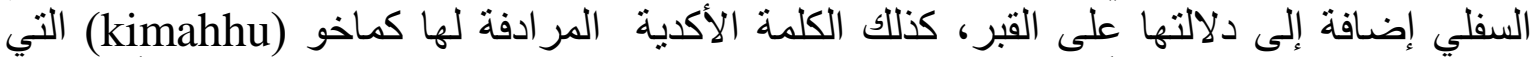

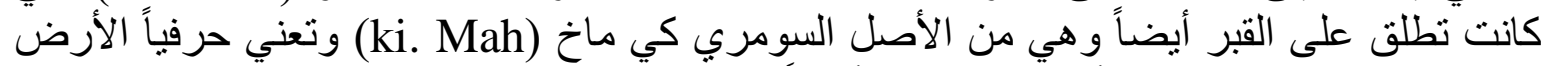

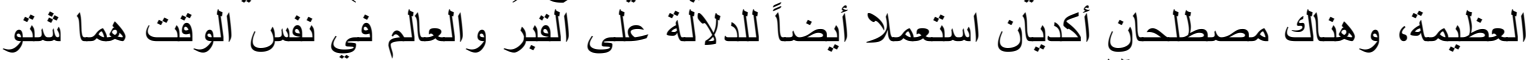
17 (hurru) وخرو (suttu)

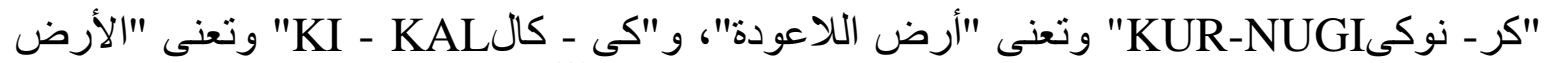

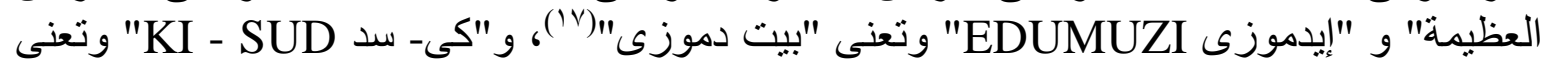

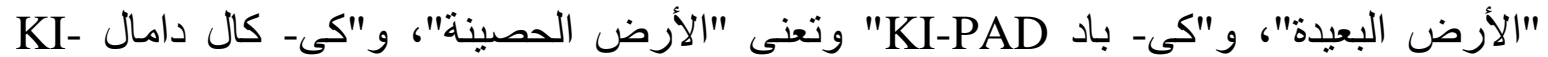
GALDAMAL

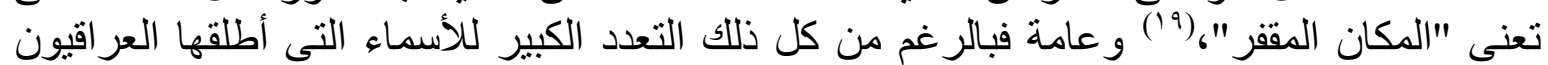

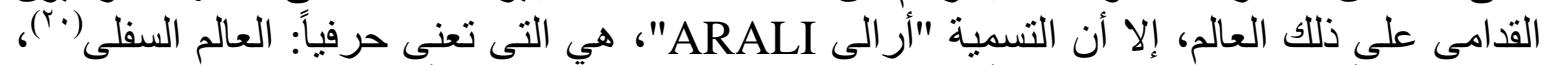

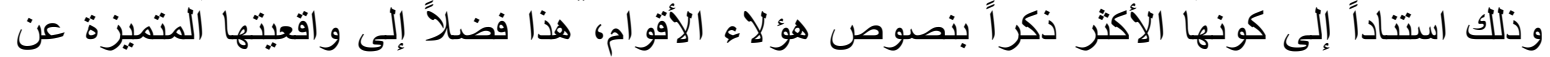

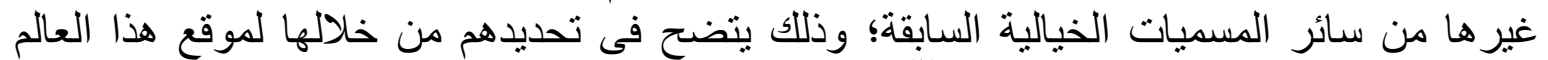

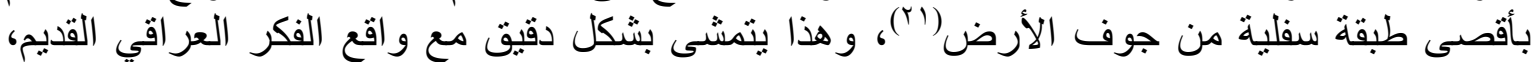

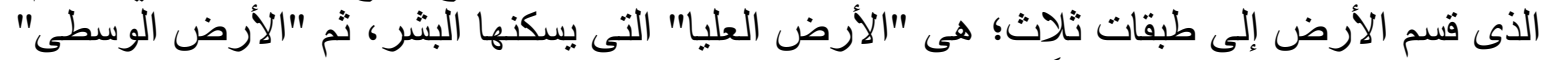

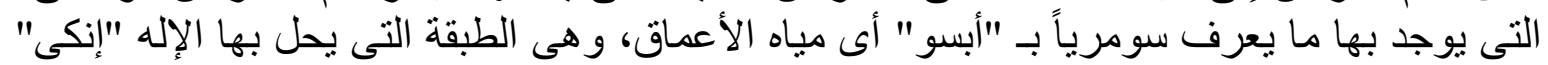

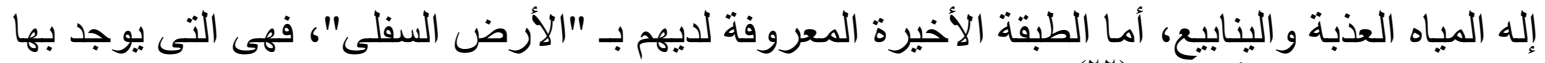

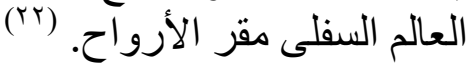

\section{موقع العالم السقلي}

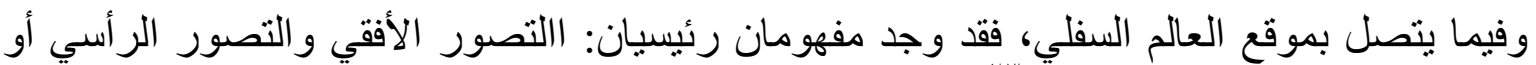

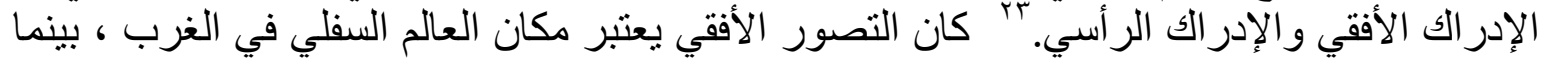

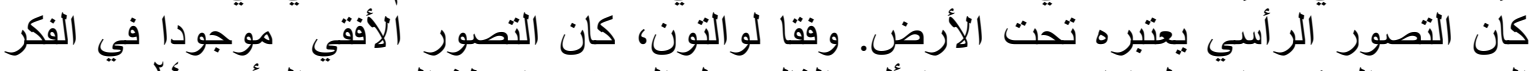

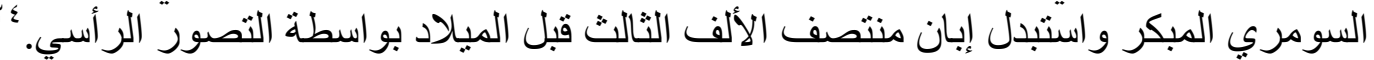

تقول كاتز بأن التصور الرأسي ليس سومريًا في الأصل، ولكن تم تطويره بناءً على التصور الأفقي

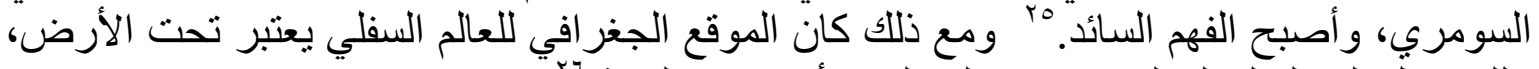

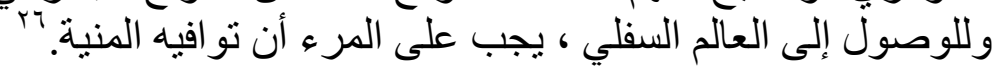

تميل الباحثة إلى التصور الر أسي لموقع العالم السفلي فهو سومري الأصل على النقيض من كاتز حيث

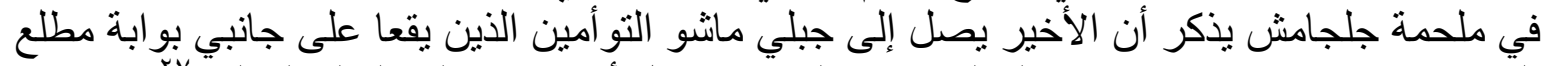

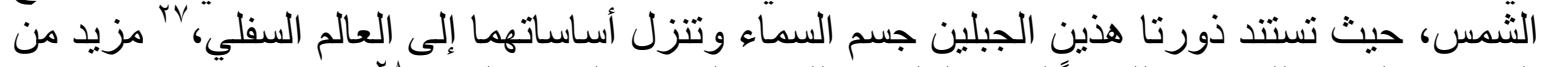

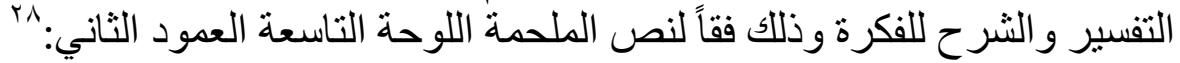

اسم هذا الجبل، هو التو (أمان)

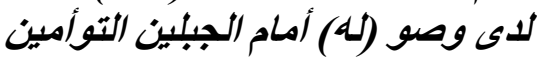

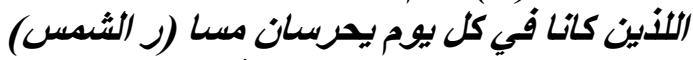

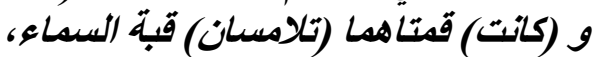




\section{بينما كانت قاعلتهما تستقر في العالم السفلمي.}

ويتضح من خلال سياق النص أن قو اعد الأعمدة تستقر في الأسفل بشكل رأسي وذلك لطبيعة العمود

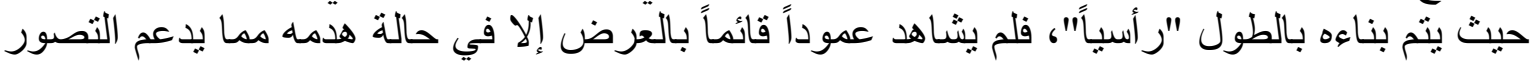
الر أسي للعالم السفلي.

كذلك في اسطورة نرجال و ايرشيكجال فيما يذكر

$$
\begin{aligned}
& \text { في يوما ما، ويينما كانوا على وشكك الإعداد لوليمتهم }
\end{aligned}
$$

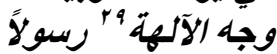

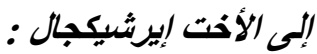

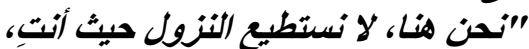

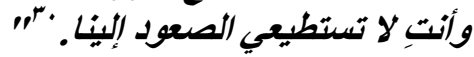

ومن خلال ذكر مصطلحات النزول و الصعود يتضح التصور الر أسي أقرب لموقع العالم السفلي.

تربط كاتز التصور الر أسي إلى هبوط الثمس في العالم السفلي للحكم على الموتى. اب تذكر كاتز أيضا

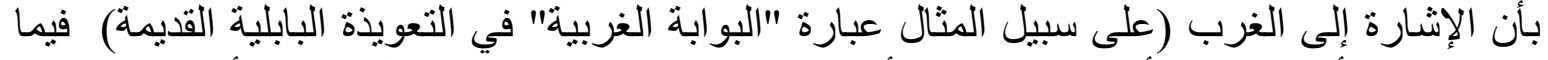

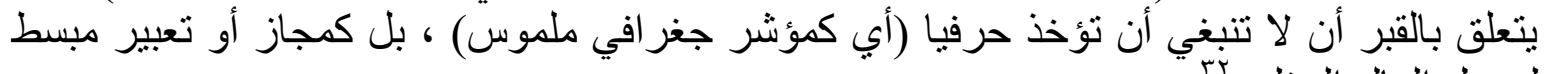

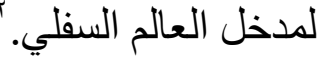

قسم سكان بلاد ما بين النهرين القدماء الكون إلى ثنلاثة أقسام الأول منها السماء، التي اعتبرت مقراً

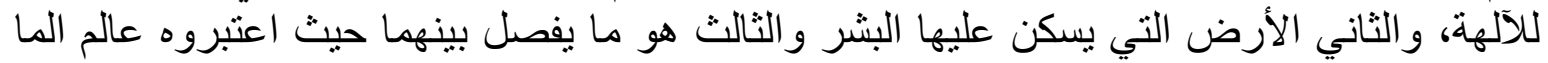

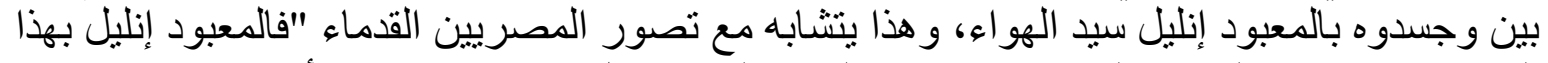

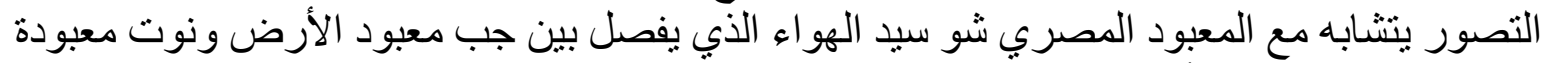

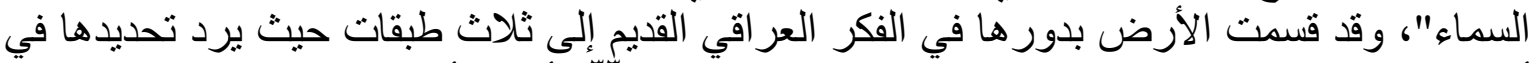

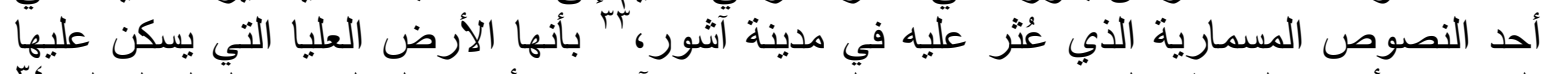

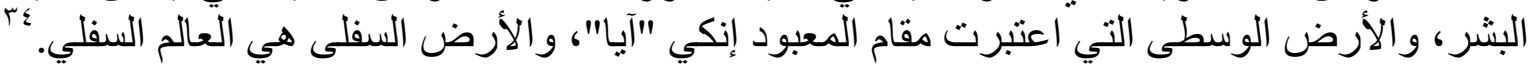

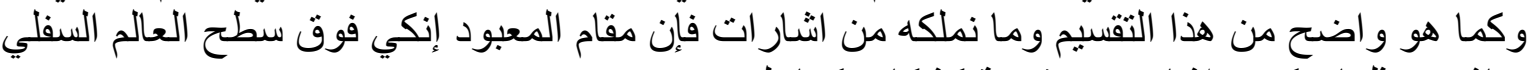
مباشرة مثلما عكسته اشارة في فو فصة كثكانو كما يلي:

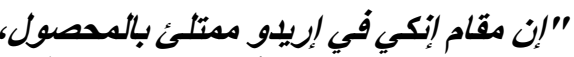

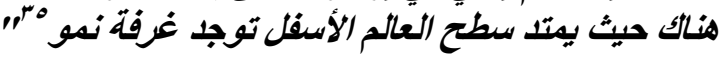

بعد ترصد كيفية نشوء الكون والعالم عند السومريين من خلال الآلهة و أجيالها، يمكن تخيل طبيعة هذا

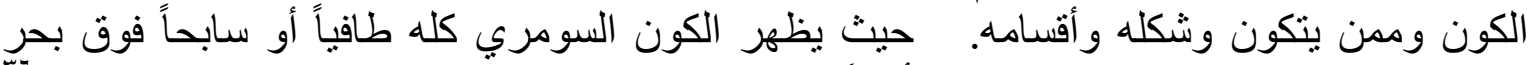

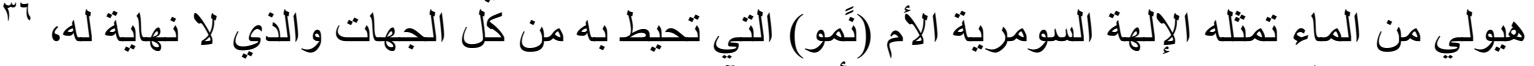
في حين كان الكون كرة عملاقة تتكون من الأقسام الآتية :

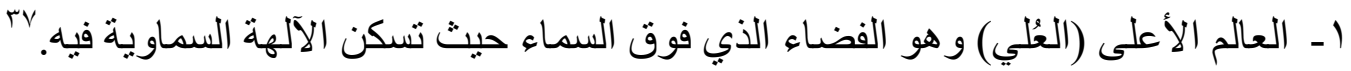

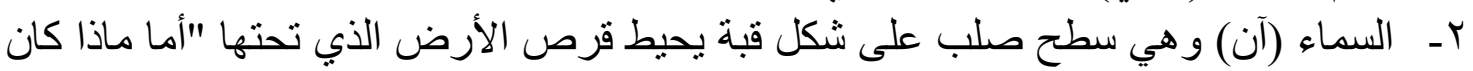

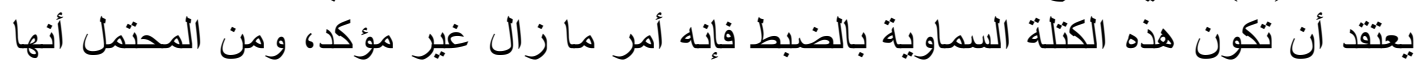

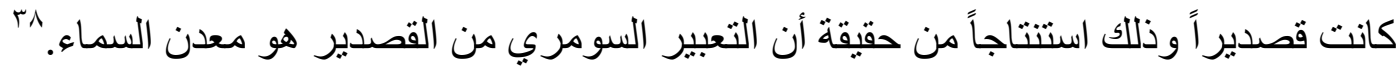




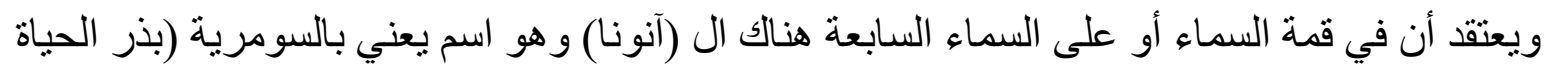

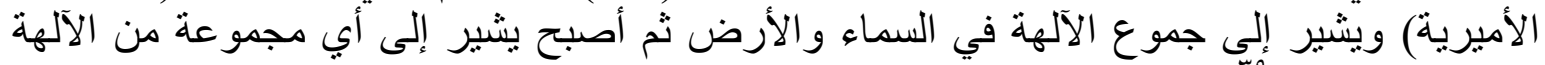
حتى المحلية منها.

rـــ الفضاء (ليل Lil) و هو الفر اغ الموجود بين السماء والأرض وكانت كلمة ليل تدل على الظلمة

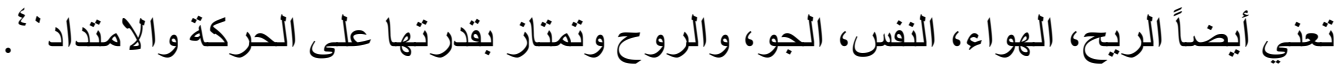

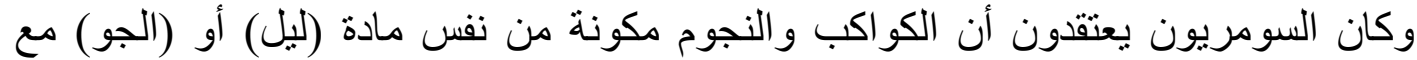

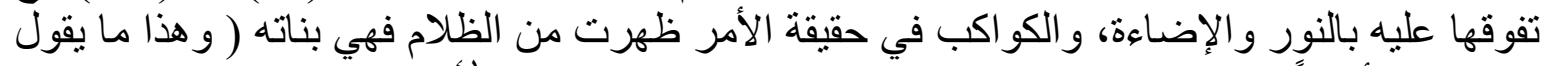

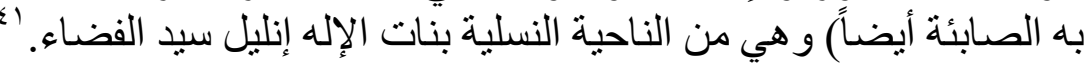

ويبدو أن السومريون حددوا في زمنهم ثلاث طرق أو مسارات في هذا الفضاء، هي (طريق آن،

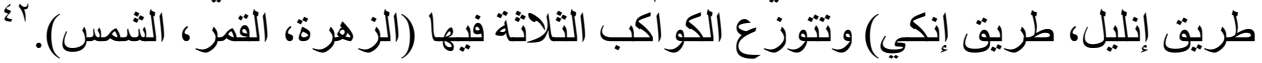
ــ الأرض (كي Ki) وهي قرص مدور منبسط يطفو على محيط مائي حوله وأسفله، ويمكن

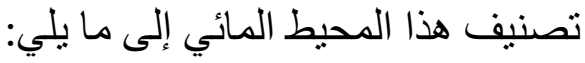

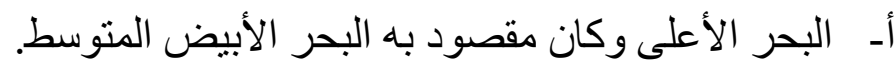

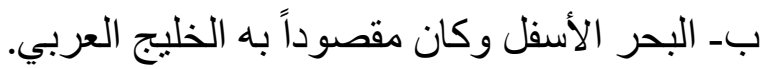

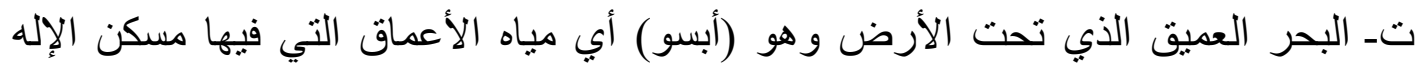

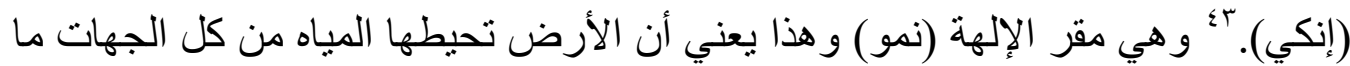

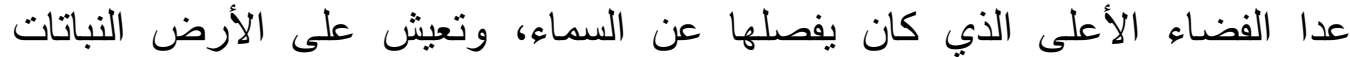

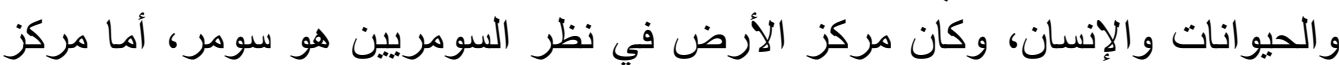

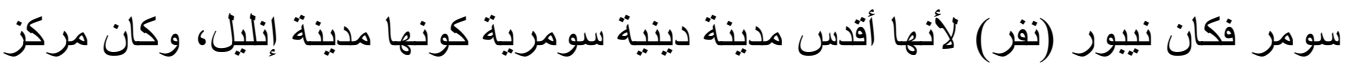

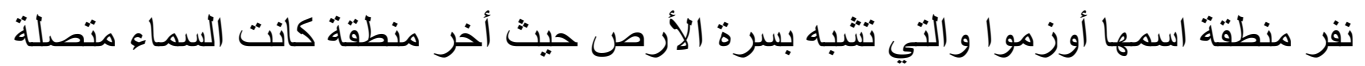

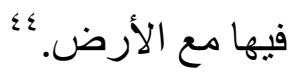

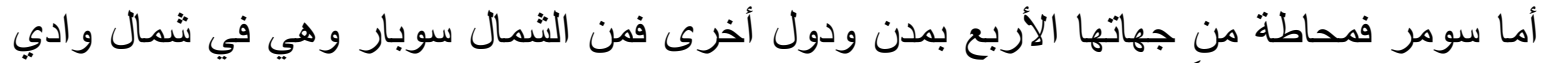

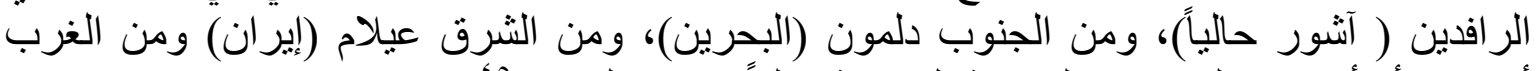

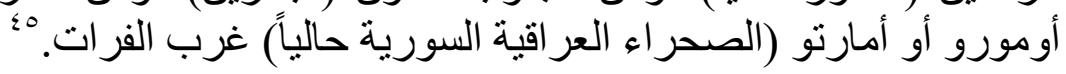

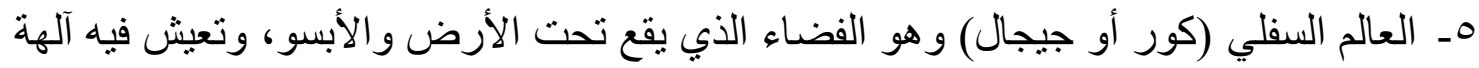

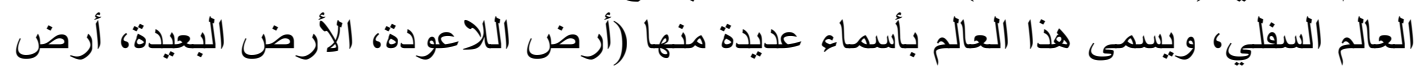

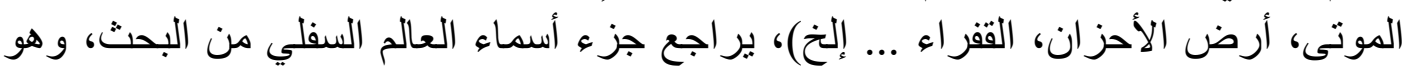

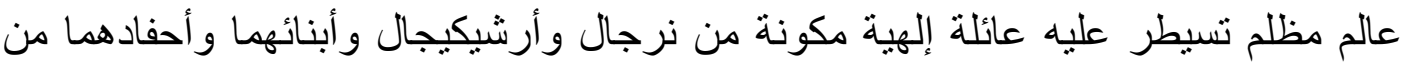

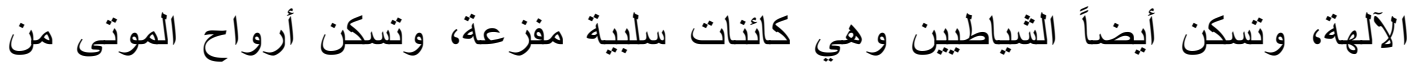

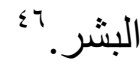

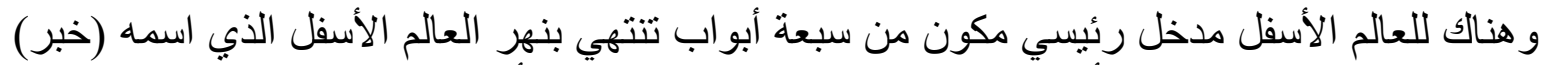

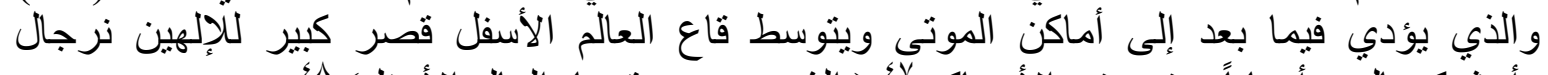

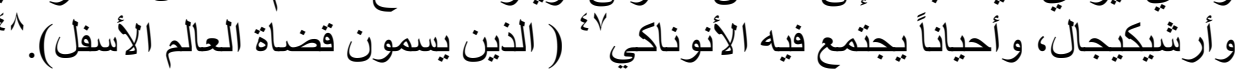




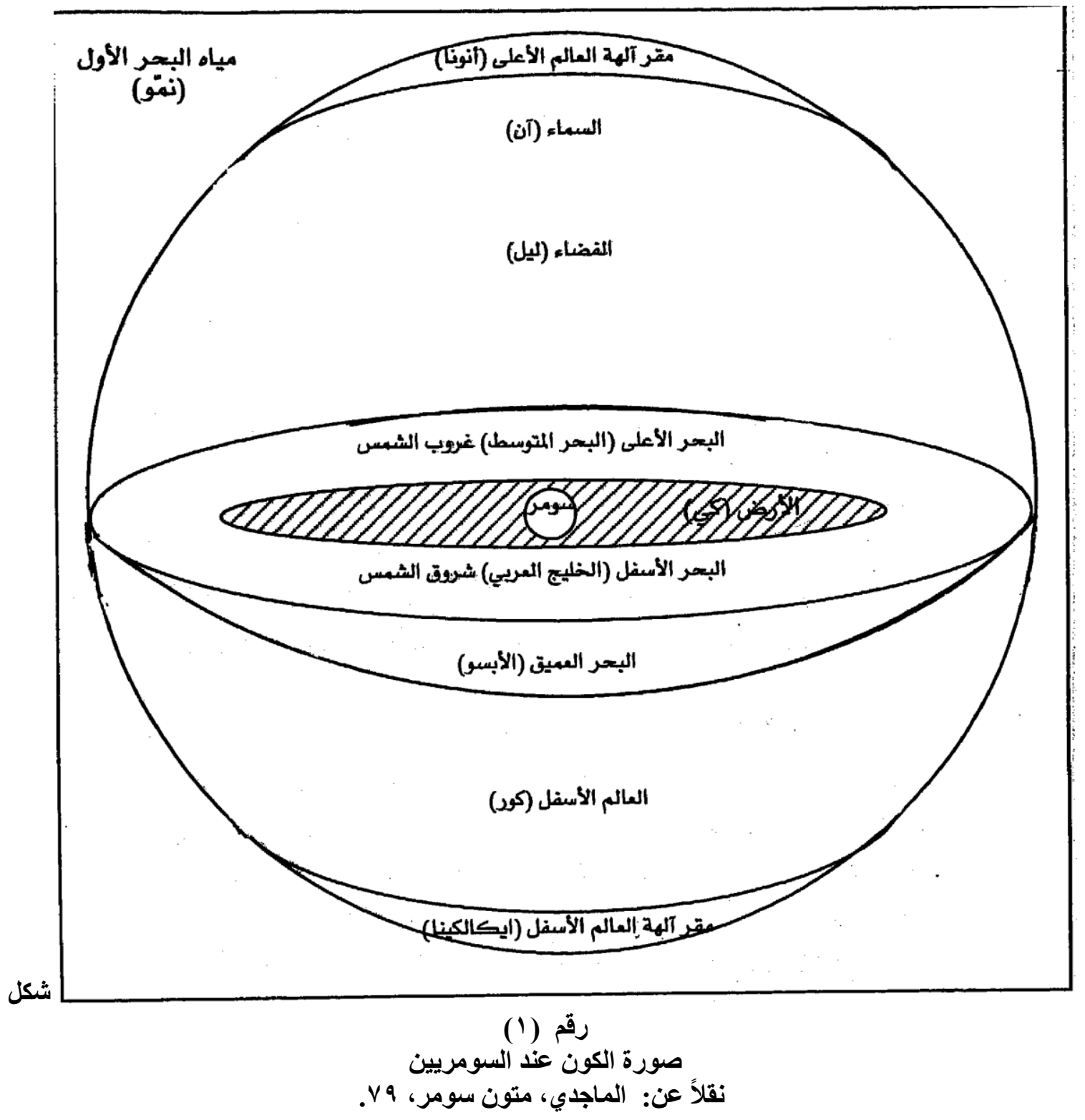

إن هذا التصور الميثولوجي للكون يضع الأرض في المركز ويتصور ها مثل قرص مسطح (فيه

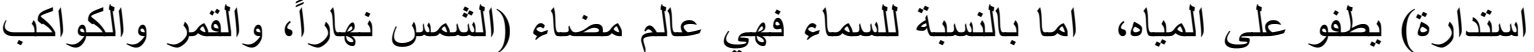

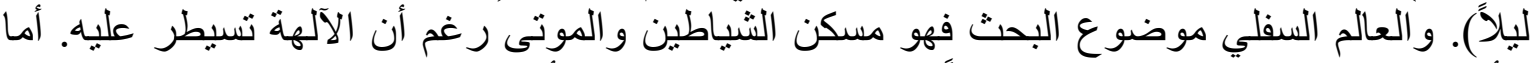

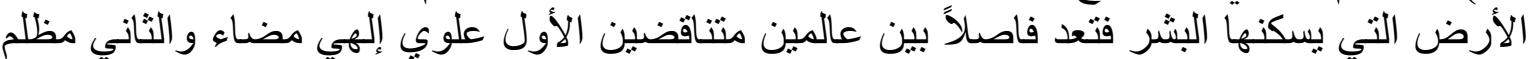

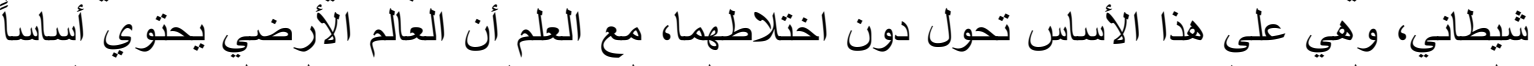

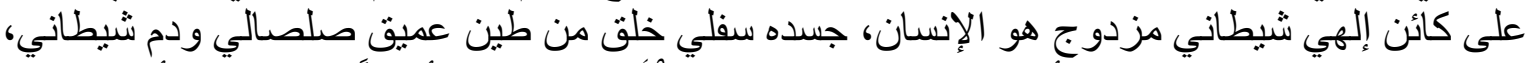

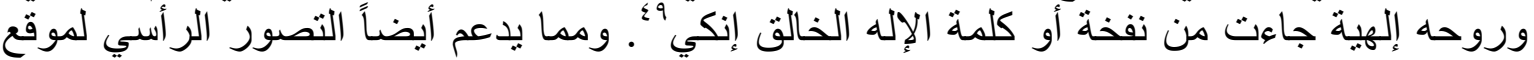
العالم السفلي.

و عند تتبع مصطلح الجبل "كر" أو كور إحدى مسميات العالم السفلي وهو مصطلح سومري ير ادفه

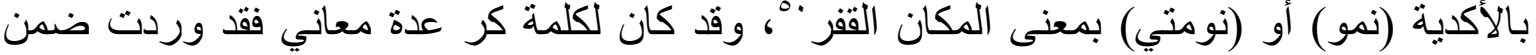
إثنارة موجزة في مقدمة الأسطورة السومرية "جلجامش و إنكيدو والعالم الأسفل" باعتبار ها اسم لوحش 


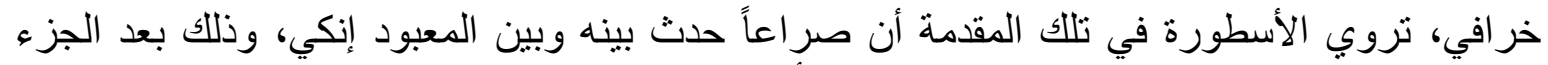

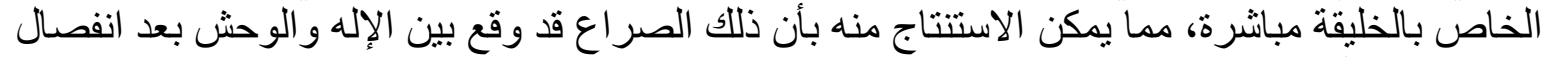
السماء عن الأرض.

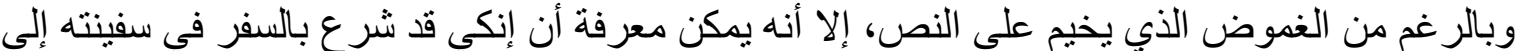

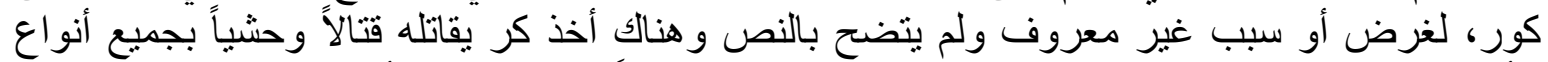

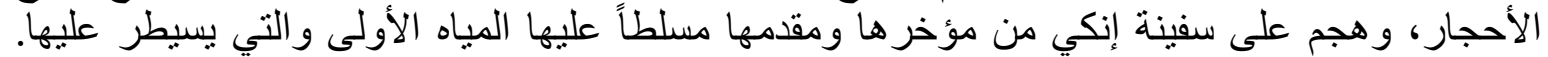

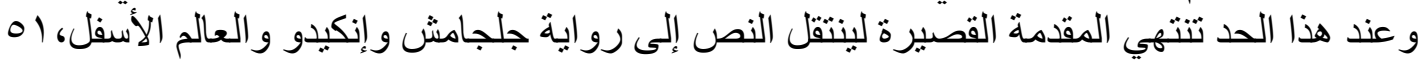

كما أنها توجد في العديد من النصوص الكتابية لتعني البلاد الأجنبية، إلا أن المعنى الذي يعتقد أن لله علاقة

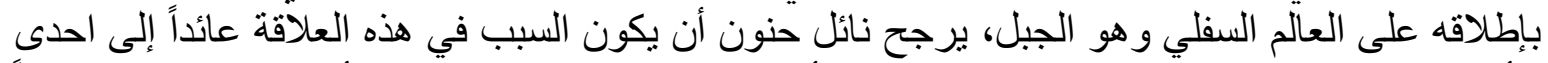

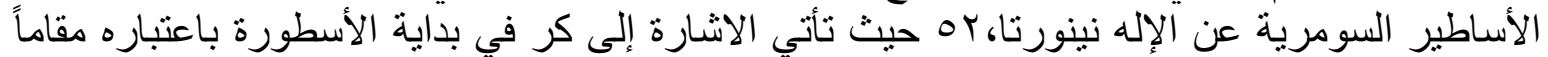

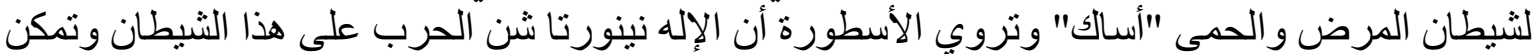

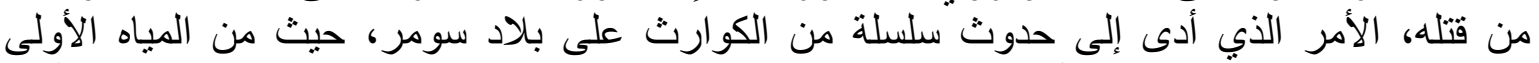

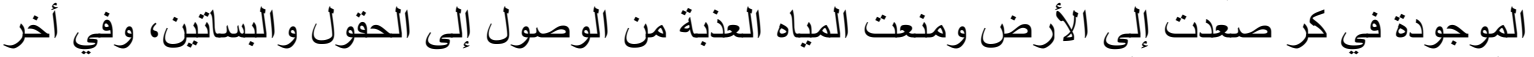

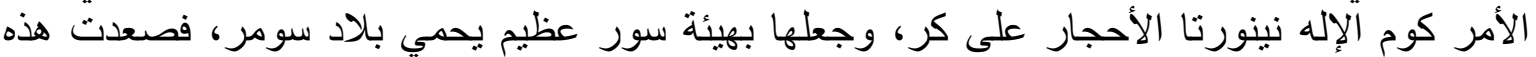

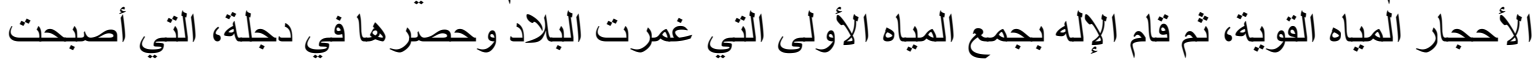
الآن قادرة على ري الحقول. الحهاه

و وتكريماً للمعبودة نينخورسنج "سيدة الجبل"، فقد حمى المعبود نينورتا السد الذي قامت بيناءه نينخورسنج

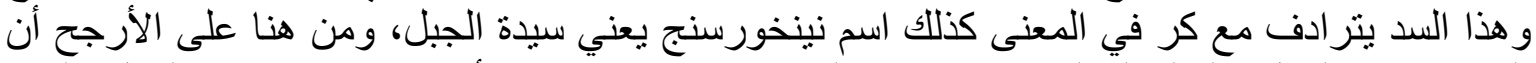

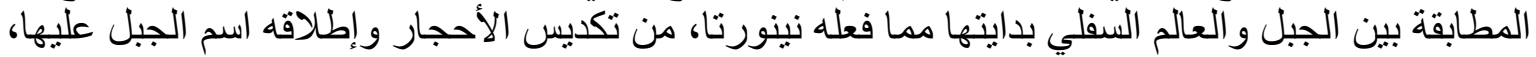

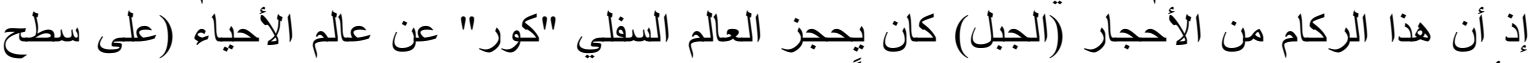

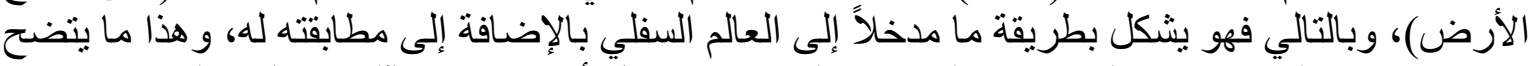

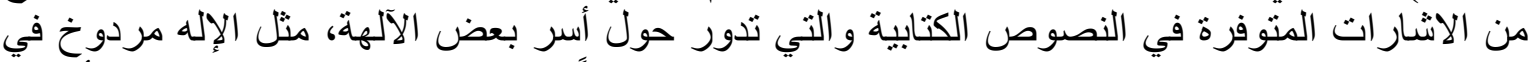

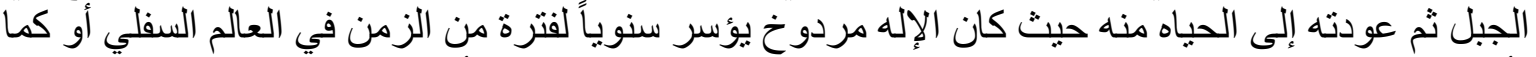

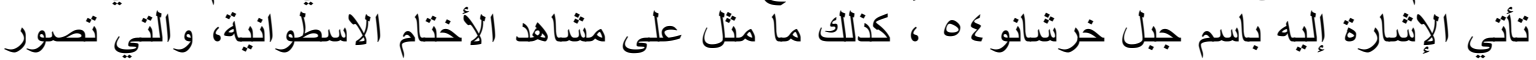

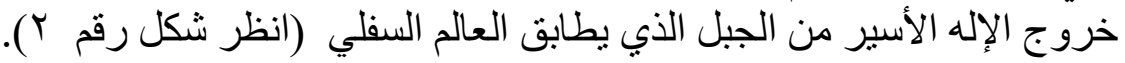
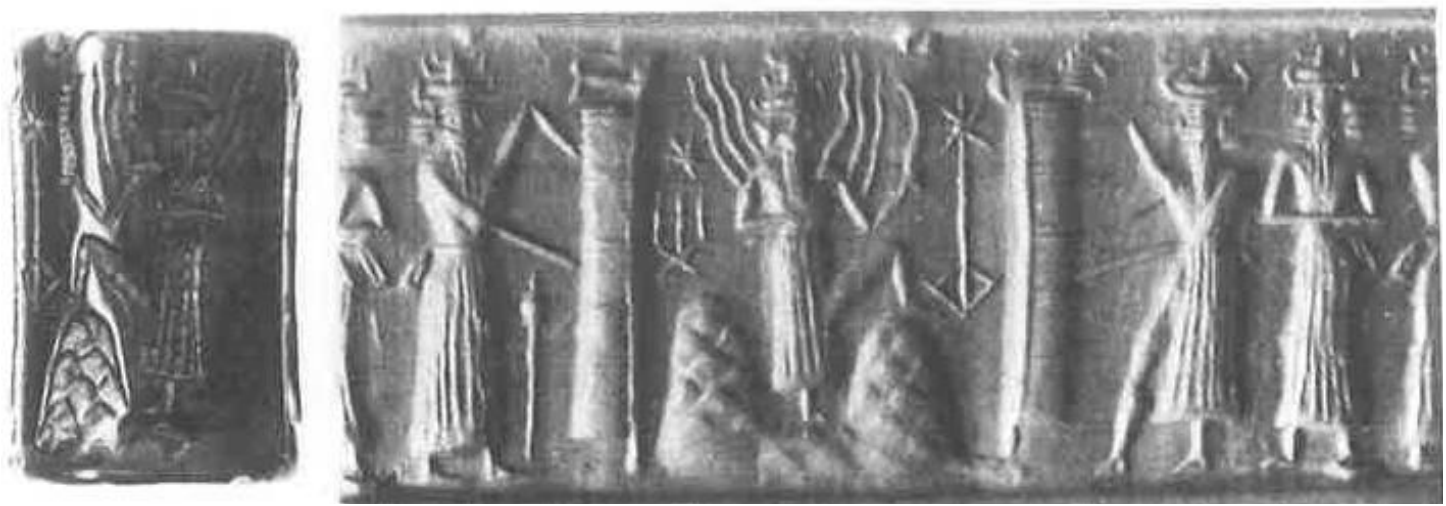

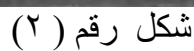

خروج مردوك من الجبل على ختم أسطو اني من حجر السربنتين

نقاً عن Collon. Dominique, Catalogue of the Western Asiatic Seals in the British Museum, Cylinder Seals II, Akkadian- Post Akkadian -Ur III, British Museum, 1985, PLATE XXV, 172, 89110 


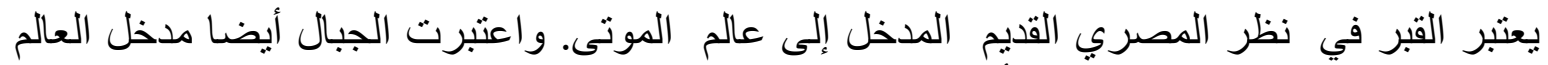

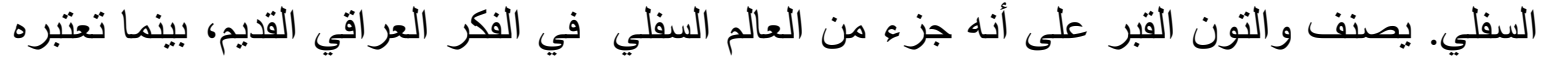

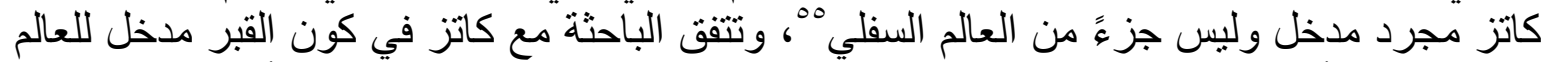

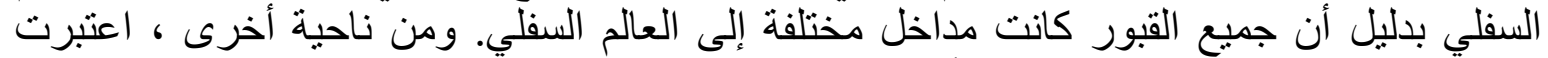

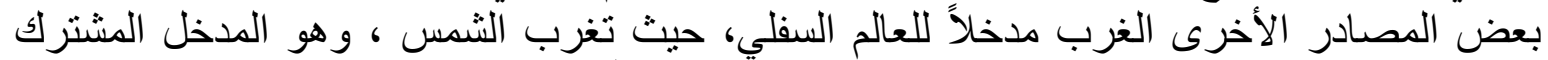
للعالم السفلي في العقيدتين الدصرية القديمة و العر اقية القديمة.

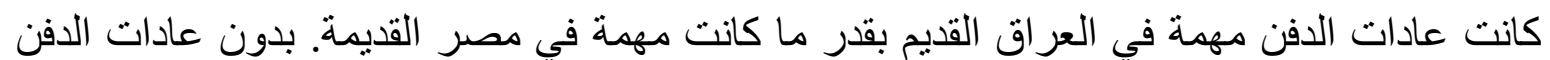

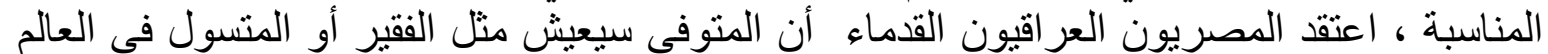

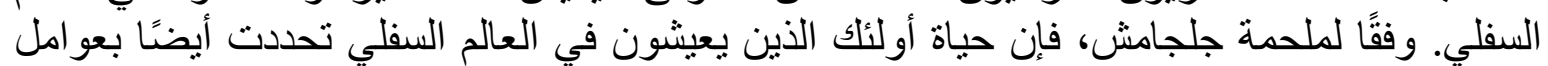

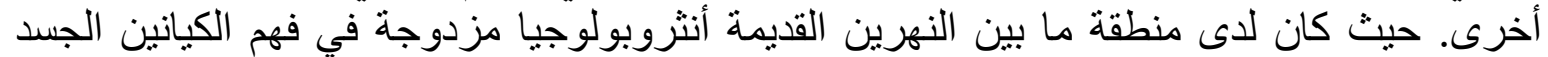

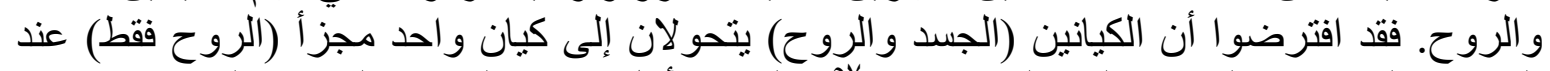

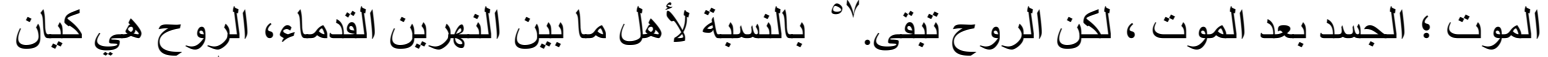

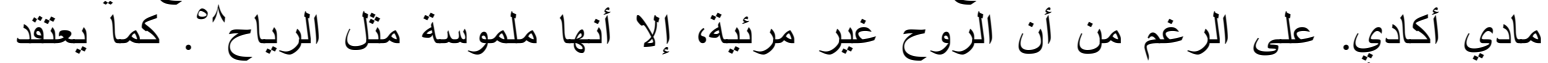

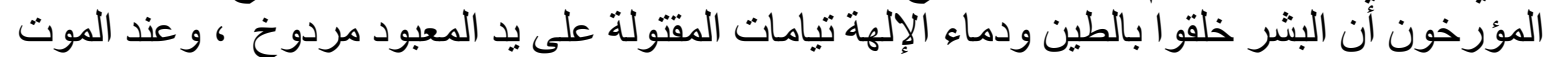
عندما ينفصلون عن اللحم (الطين) يصبح الإنسان "شبحا".

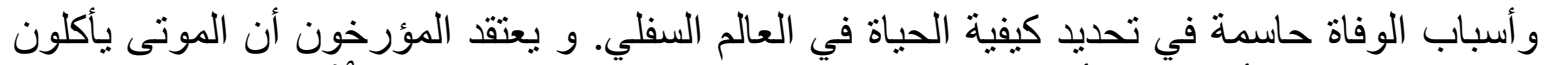

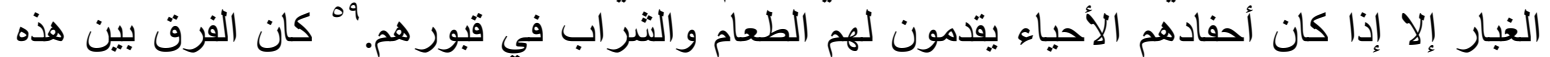

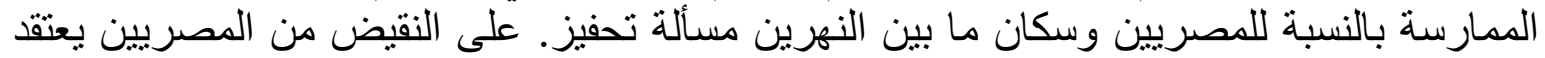

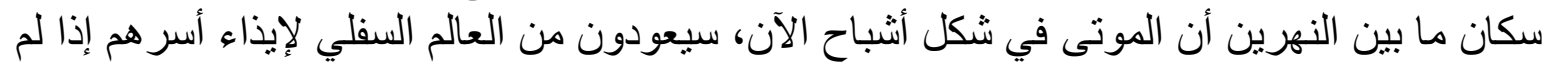

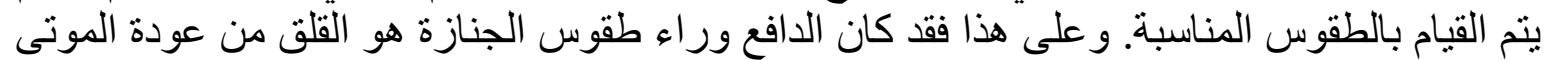

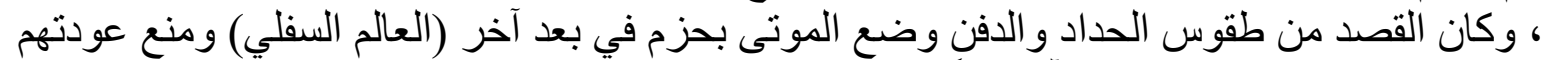

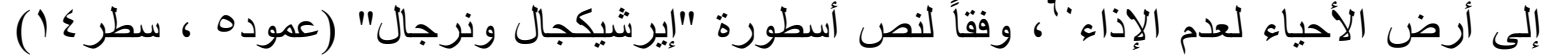

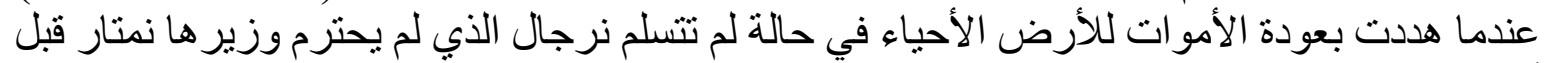
أن يصبح زوجها وحاكم العالم السفلي كما يذكر:

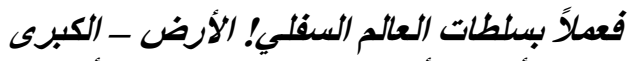 \\ سوف / جعل الأموات بصعدون لالتهام الأحياء

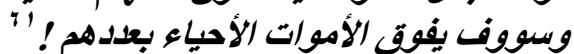

وكان هذا التهايد قد تلفظت به عشتار من قبل في اسطورة نزول عشتار إلى العالم السفلي النص الأكادي عندما وصلت لبو ابة العالم السفلي ورغن فيت بالدخول كما يذكر النص:

$$
\begin{aligned}
& \text { لاى وصولها إلى بوابة بلد - اللاعودة } \\
& \text { وجهت إلى حارس الباب هذه الكلمات: }
\end{aligned}
$$

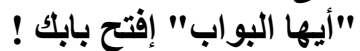

$$
\begin{aligned}
& \text { افتح الباب كي أدخل، أنا التي أكلمك؛ }
\end{aligned}
$$

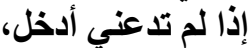

$$
\begin{aligned}
& \text { سوف أدفع الباب، حتى كسر المزاليج، } \\
& \text { وسوف أزعزع منه القو ائم، حتى تحطيم المصر اعين، } \\
& \text { وأجعل الأموات يصعدون } \\
& \text { فيلتهمون الأحياء، } \\
& \text { إلى درجة يصبح معها عدد الأموات }
\end{aligned}
$$




\section{يفوق عدد الأحياء!}

و اللوح الطيني شكل (رقم ץ) المكتوب باللغه الاكاديه الذي تم العثور عليه في مكتبه آشوربانيبال

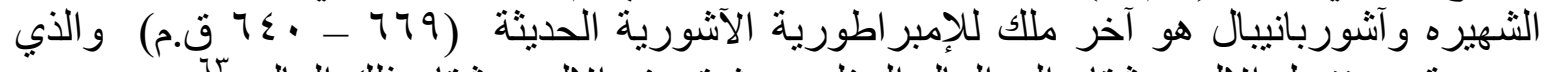

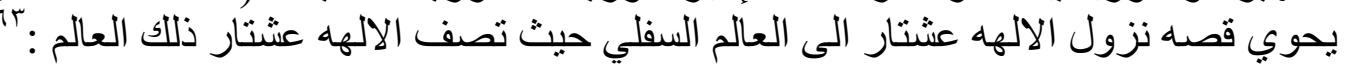

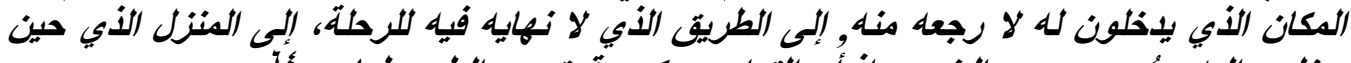

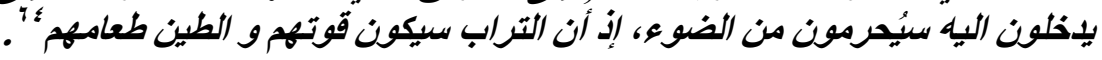

و ون خلال وصف المعبودة عشتار يتضح أن مكان العالم السفلي لا نهاية فيه مظلم وكئيب، و وعلى النى مايبدو أنه في مكان عكس المكان المضئ وهو السماء أو في الجهة المقابلة له (أسفل الأرض وض واله المياه الجوفية.

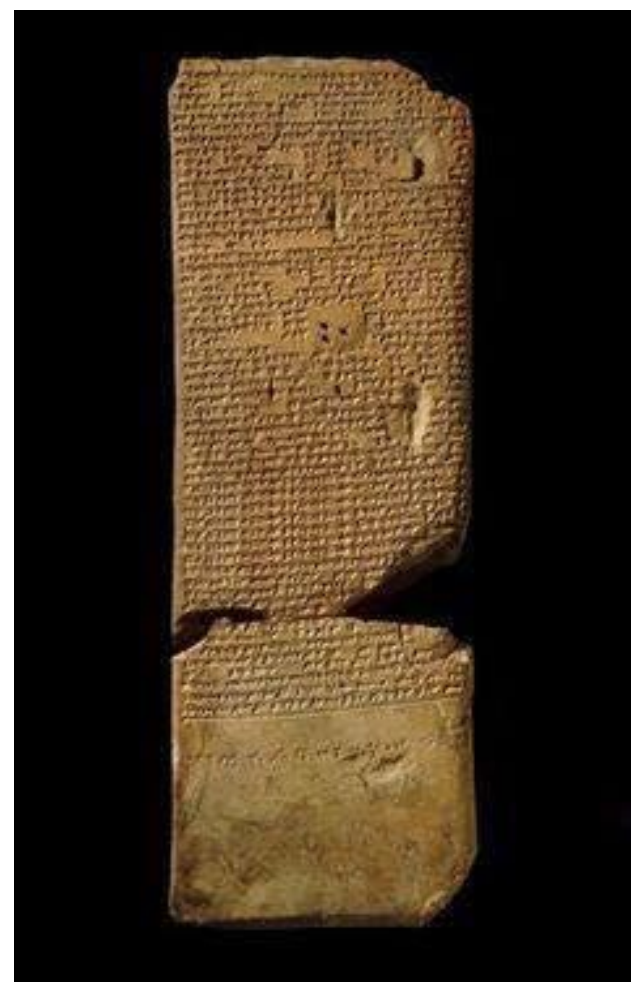

شكل رقم (r)

اللوح الطيني: نزول عثار إلى السفلي

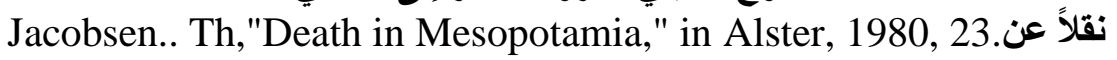

أما بالنسبة لمداخل العالم الأسفل فيمكن تحديدها وفقاً لما هو متوفر من معلومات على التحو التالي :

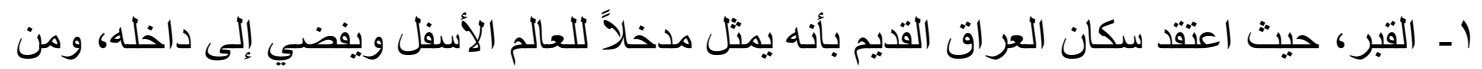

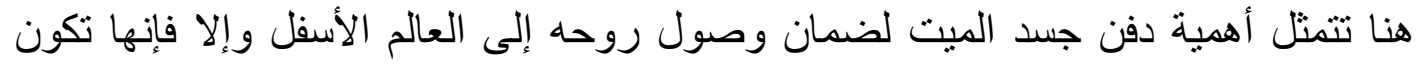

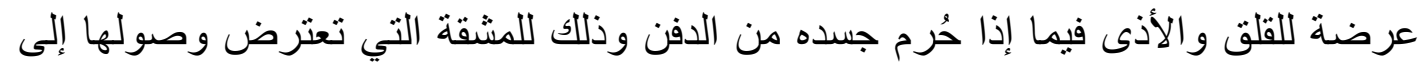
عالم الأموات. Y- و هناك مدخل آخر للعالم الأسفل يقع في الجهة الغربية البعيدة من الأرض حيث مغيب الثمس،

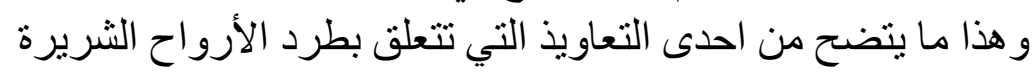


" ياشدس ! إن الثبح المرعب الذي جثم على ظهري منذ عدة أبام لا برخي قبضته عني، إنه بلاحقني طوال النهار

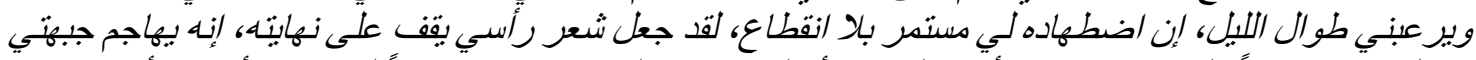

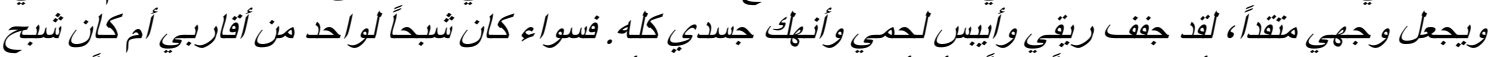

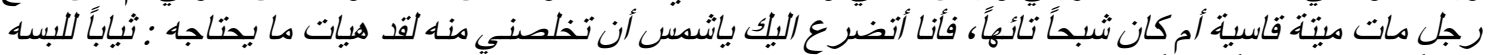

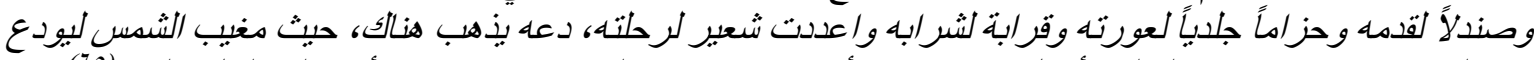

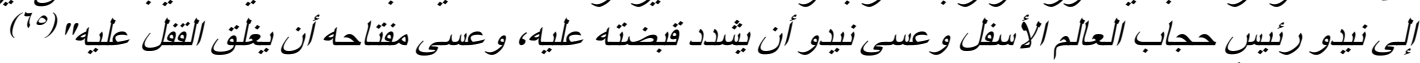

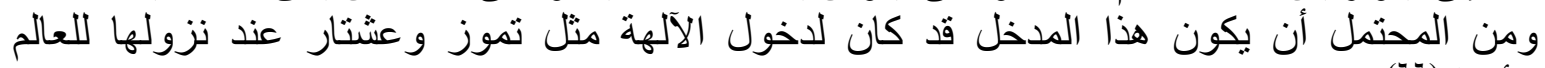
الأسفل(74) (74) r- هنالك بوابات خاصة تفضي إلى العالم الأسفل في بعض المدن المهمة في بلاد و ادي الر افدين مثل البو ابة الموجودة في الوركاء، والتي يرجح أن إنكيدو قد دخل منها إلى العالم الأسفل ليأتي

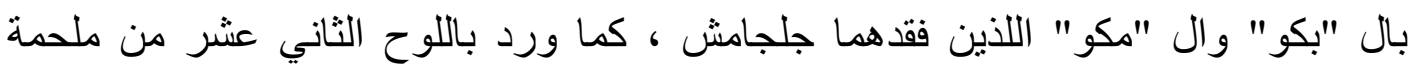

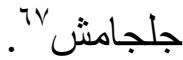
ع - و هناك إمكانية العبور من و إلى العالم الأسفل بواسطة أي حفرة عميقة في الأرض، وذللك وفقاً

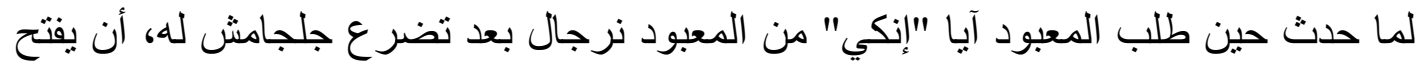

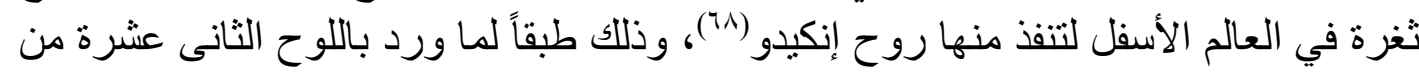

$$
\begin{aligned}
& \text { افتح فتحة الآن بالعالم السفلى، }
\end{aligned}
$$

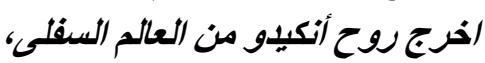

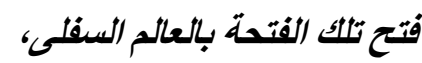

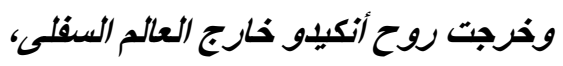

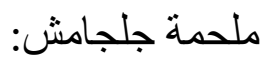

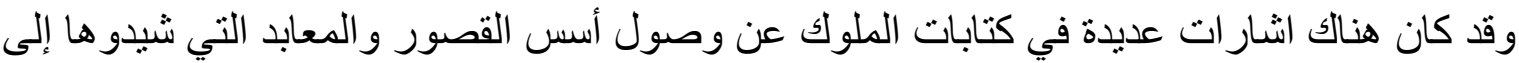

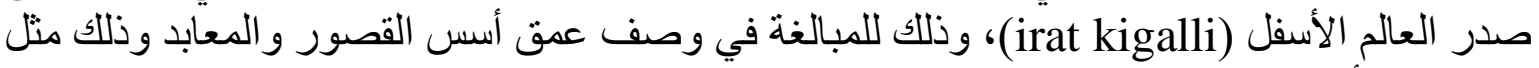
ما ورد في أحد نصوص الملك سرجون حيث يذكر :

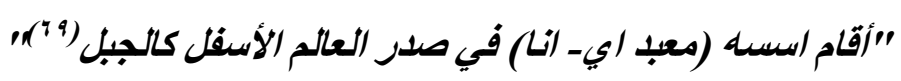

وبالرغم من أن هذه الاشارات تعتبر دليل على رسوخ أسس البناء إلا أنها تحمل في طيأتها صورة و اضحة عن عمن العن عن العالم الأسفل.

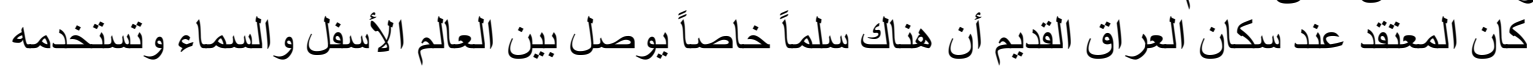

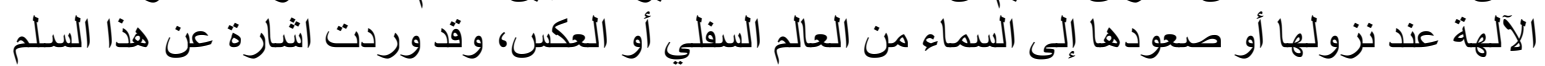

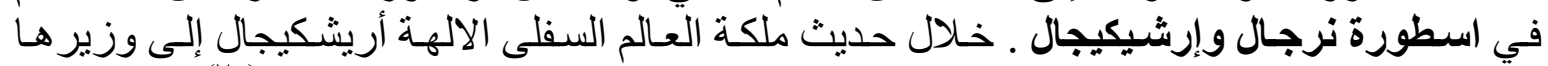

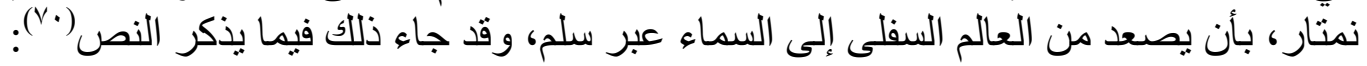

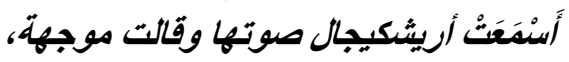

$$
\begin{aligned}
& \text { كلماتها لوزييرها نمتار: }
\end{aligned}
$$

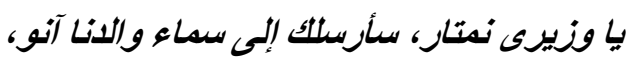

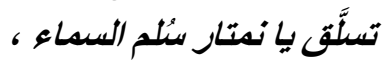

و على أي حال فكل تللك المداخل السابقة تؤل بالأرواح إلى العالم السفلى، الذى تخيله العر اقيون القداءماء ، التهاء

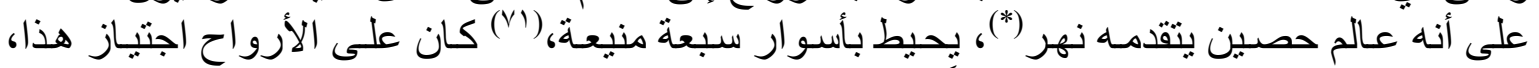

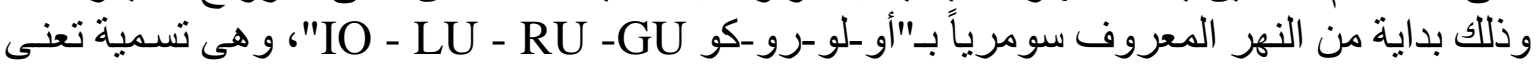


"نهر العبور البشرى"،(rr) بينما أطلق عليه الأكديون - فيما بعد ـ اسم "حبرون"، وذكروا بأنـه يوجد

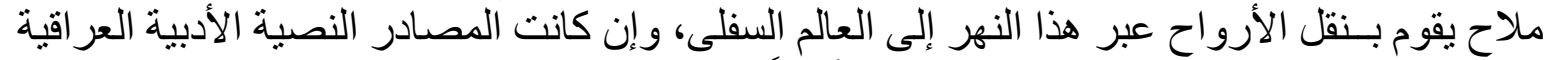

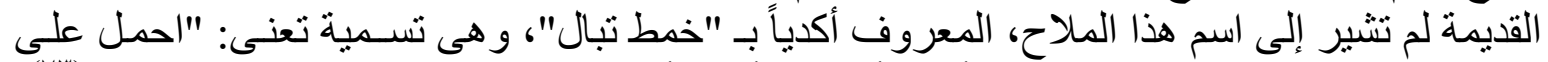

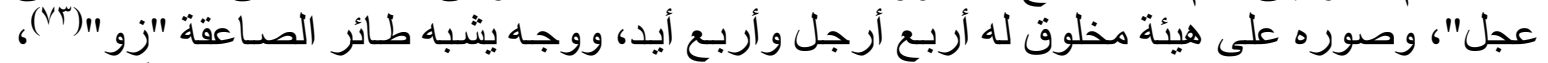

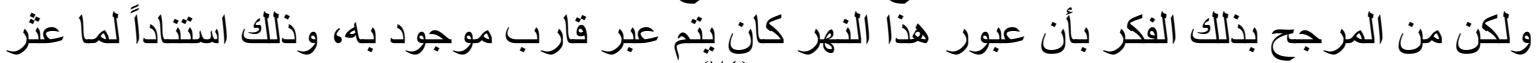

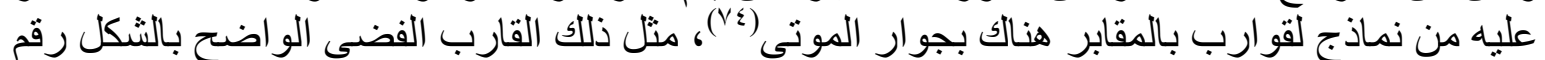
ع)، الذى عثر عليه بأحد مقابر أور الملكية(10).

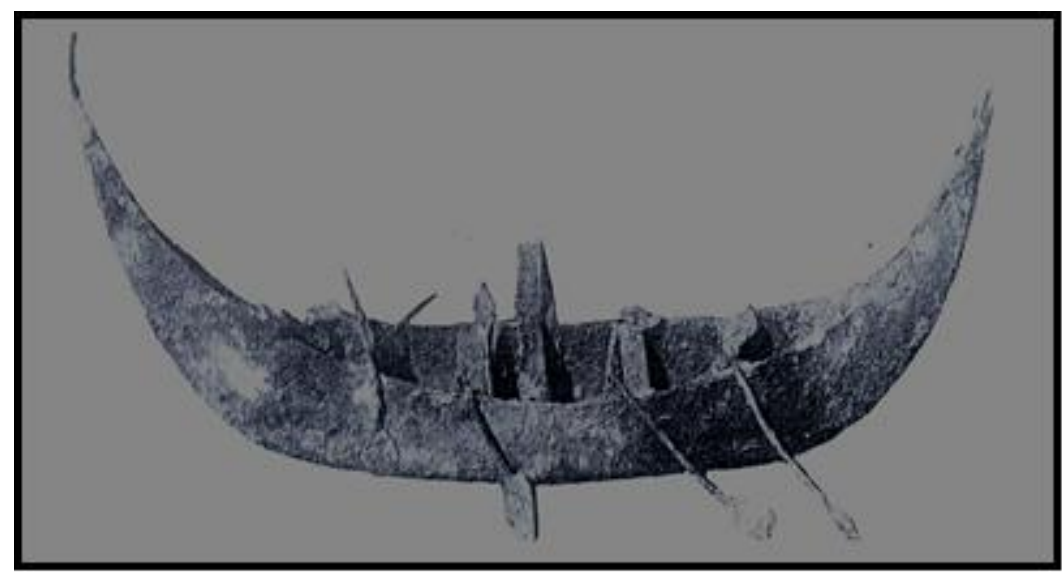

Hall, H. R., the Ancient History of the Near شكل رقم (ع) إحدى المر اكب التي وجدت بمقابر أور الملكية نقلاً عن East, London, 1947, 69

وبعد عبور الأرواح لهذا النهر، كان عليها أن تتوجه إلى أسوار العالم السفلى، بأن تُحمل إلى هنالك فوق

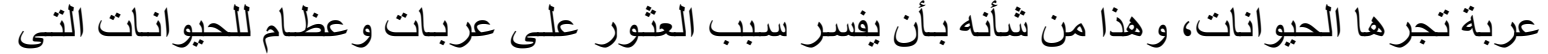

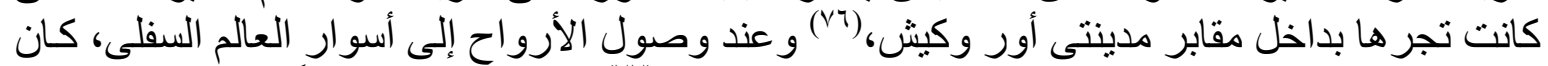

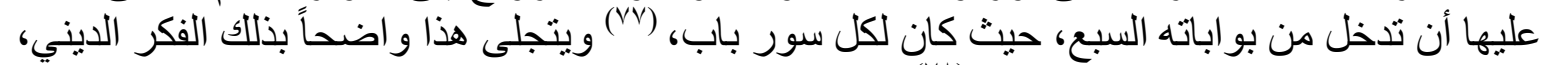

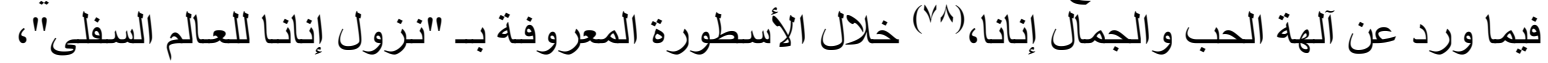

$$
\text { "البوابات السبع للعالم السفلى إفتح أقفالها"، (199) }
$$

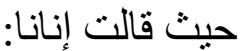

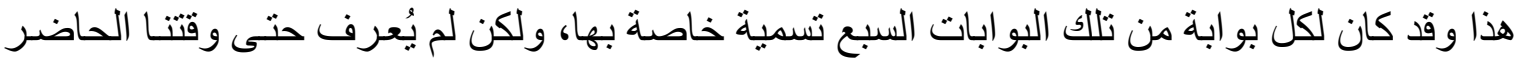

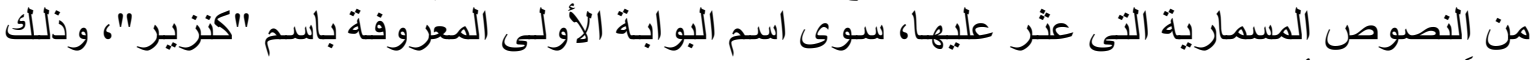

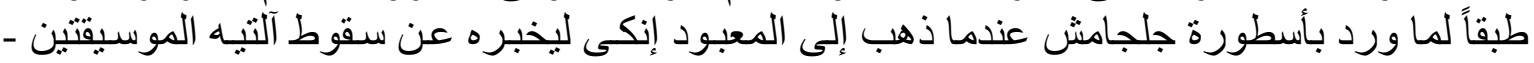

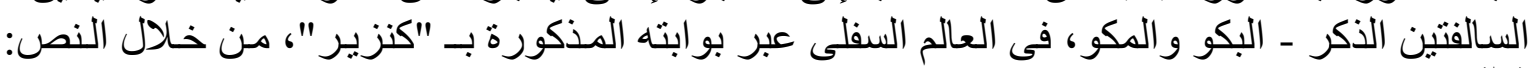

$$
\begin{aligned}
& \text { - أبها الأب إنكى، لقد سقط بكو فى العالم السفلى، } \\
& \text { - وسقط مكو فى كنزبير، ل }
\end{aligned}
$$

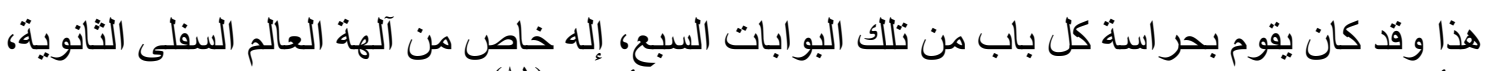

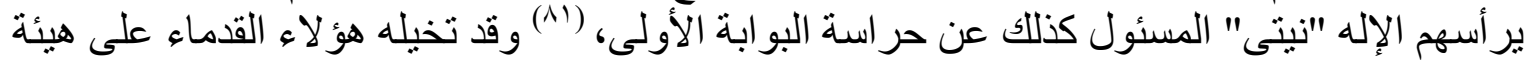

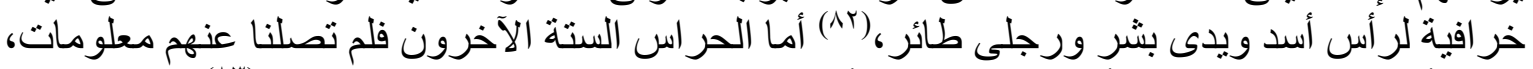

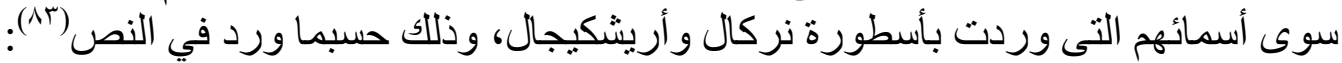




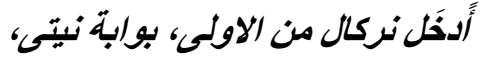

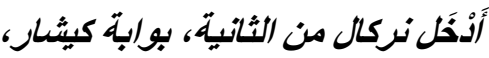

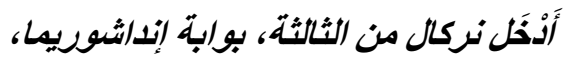

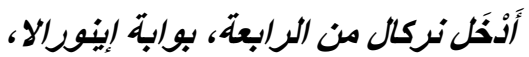

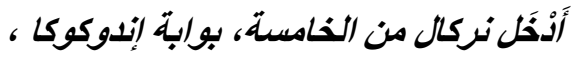

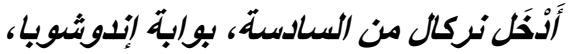

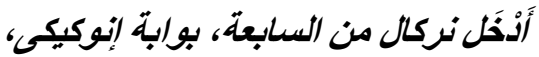

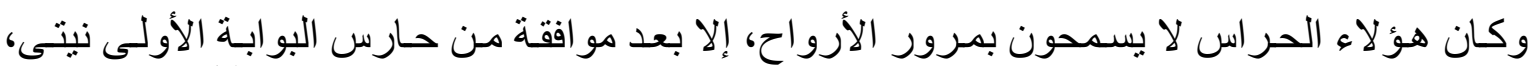

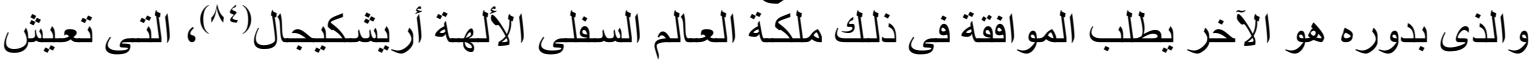

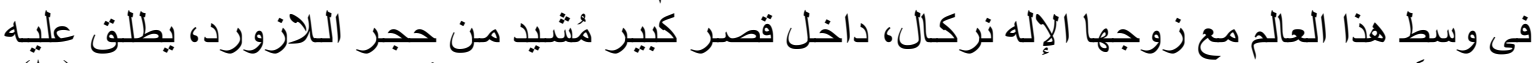

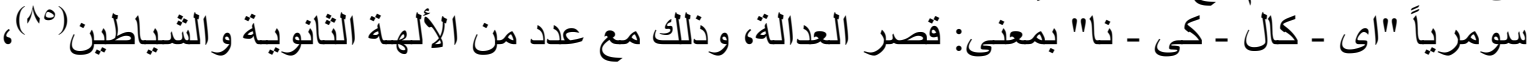

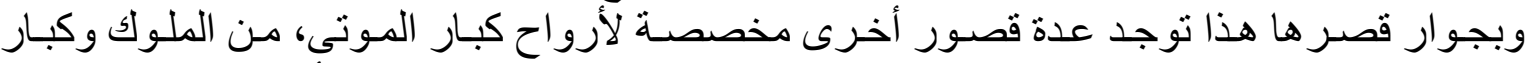

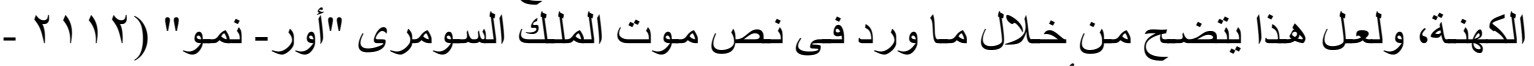

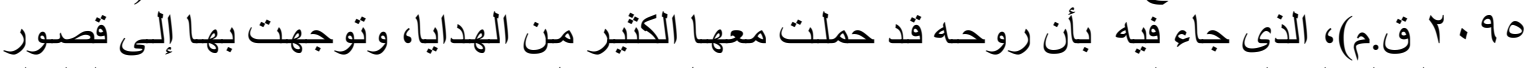

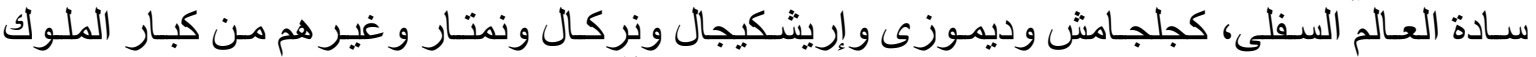

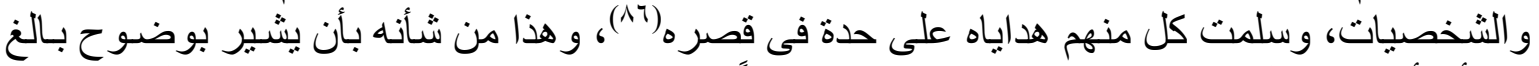

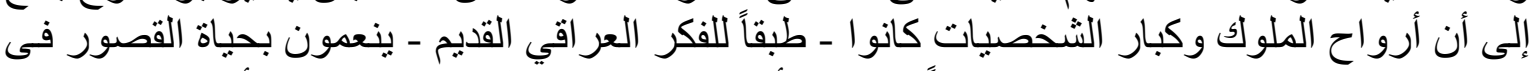

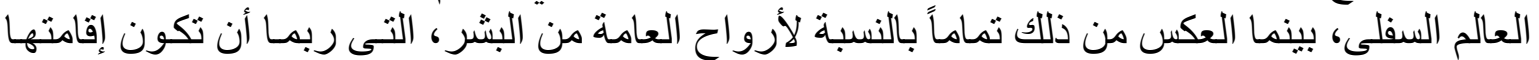

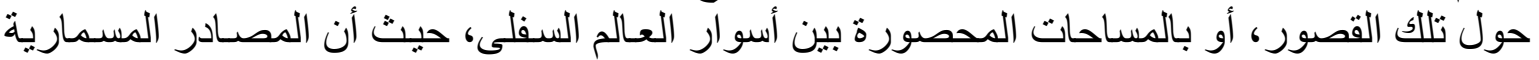

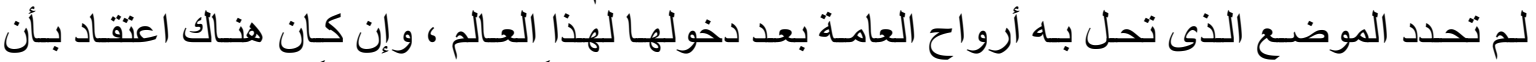

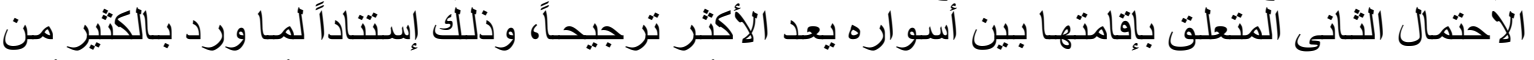

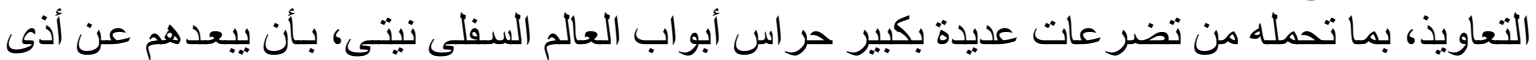

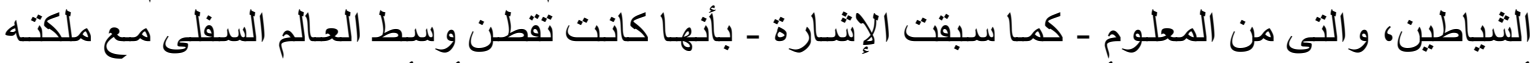
أريشكيجال، و هذا يدل على أن العر اقيين القدامى كانو ا يعتقدون بالفعل بأن أرواح العامة كانت التهان تقيم بين

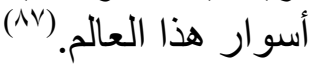

\section{نظام وقوانين العالم السفلي}

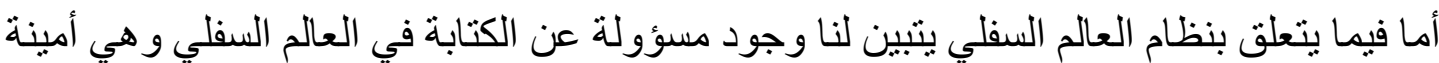

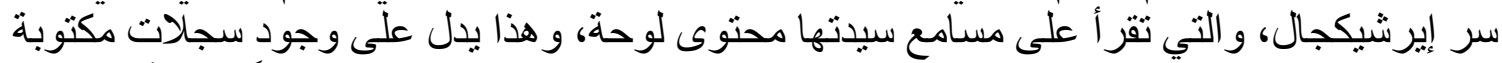

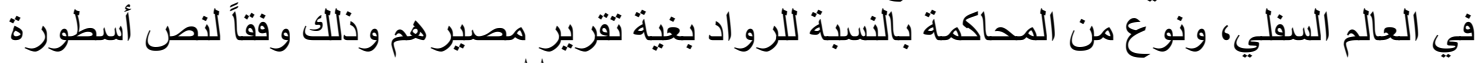

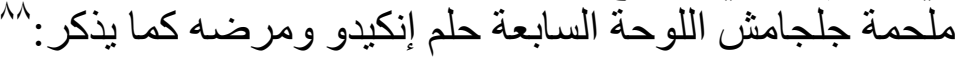

$$
\begin{aligned}
& \text { وكاتت تسكن (أيضاً) (مل)كة العالم } \\
& \text { السفلي إيرشيكجال } \\
& \text { وبيليت - صبيري كاتبتها } \\
& \text { وهي منحنية امامها } \\
& \text { كانت تصسك (لوحة) } \\
& \text { قرات عليها محتواها بصوت عاكت عالِ } \\
& \text { (رفعت عند ذلك) (الملكة) رأسها } \\
& \text { وسلطت علي نظرها: }
\end{aligned}
$$

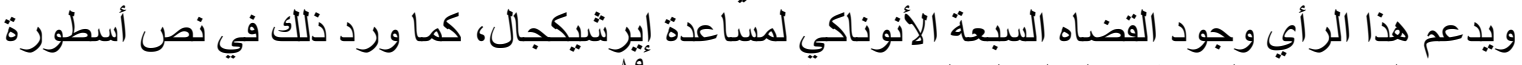

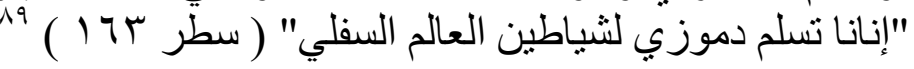




\section{أخنت عند زلك إيرشيكجال المقدسة مكاتها على عرشها

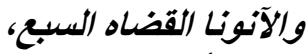

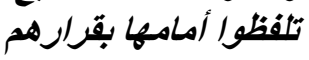

و إيرشيكجال هي أيضاً وفقاً لنص أسطورة "إيرشيكجال ونرجال" النسخة الأحدث (عموده ، سطر

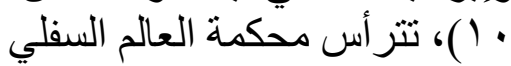

وها أنذا الآن ملوثة وغير طاهرة

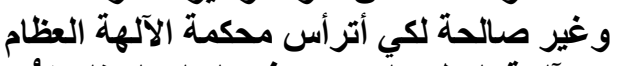

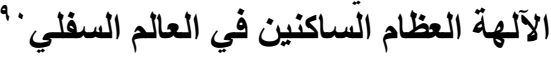

كذلك من الأدلة النصية على أن العالم السفلي له نظام إليه ما ورد في أسطورة هبوط نانا للعالم السفلي،

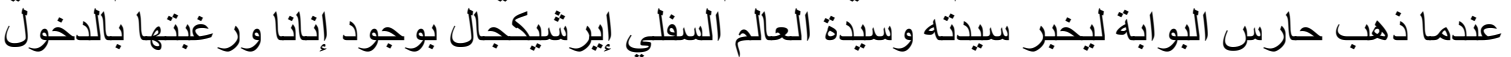

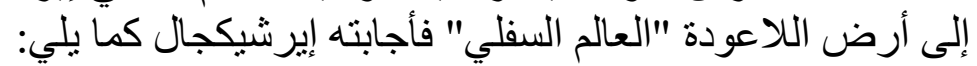

إذهب وافتح لها الباب أيها الحارس،

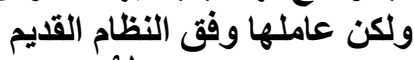

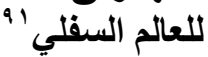

و إذا إستكملنا النص أي عند لحظة دخول عثار و عودة الحارس ليفتح لها الباب يتبين لنا النظام القديم الذي فرضته إيرشيكجال عليها كما يذكر :

$$
\begin{aligned}
& \text { "إخلي، سيدتي (قال لها) "أي الحارس لعشتار" } \\
& \text { كوتو يبتهج لاستقبالك الكاري }
\end{aligned}
$$

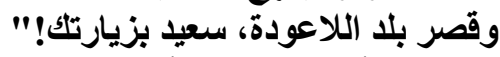

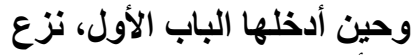

$$
\begin{aligned}
& \text { عن رأسها التاج - الكبير وصادرها } \\
& \text { لماذا، أيها الحارس (قالت) } \\
& \text { تأخذ التاج - الكبير عن رأسي؟ التئ } \\
& \text { ـأدخلي سيدتي! هكذا هو النظام } \\
& \text { المفروض من قبل ملكة العالم السفلي! } \\
& \text { حين أدخلها الباب الثاني، جرد } \\
& \text { عن أذنيها القرطين وصادر هما. } \\
& \text { لماذا، أيها الحارس (قالت } \\
& \text { تأخذ قرطي أذني؟ }
\end{aligned}
$$

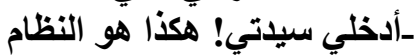

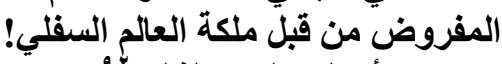

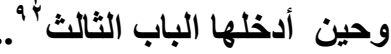

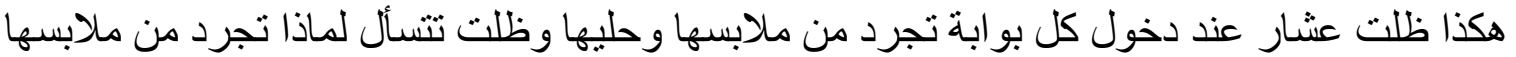
وكان رد الحارس أنه النظام المفروض من من قبل ملكة العالم السفلي.

ومن المصادر النصية التي نستدل منها على نظام العالم السفلي اللوحة الثانية عثر من ملحمة

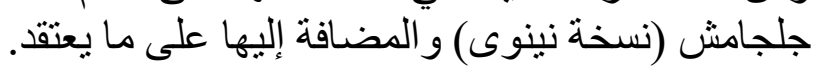

يتلخص ما يهمنا من هذه اللوحة، أن جلجامش حين أضاع المقر عة و الطبل اللذين سقطا في العالم

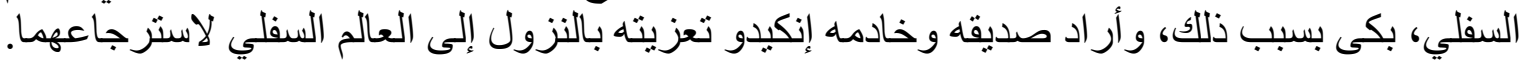
يقبل جلجامش هذا العرض، ولكنه يوصي إنكيدو بتنفيذ التعليمات و القو انين الضرورية الضية (نظام وقو انين 
العالم السفلي) لكي لا يبقى عليه سجيناً في هذا العالم ومنها عدم إرتداء ألبسة نظيفة أو الامتساح بدهون

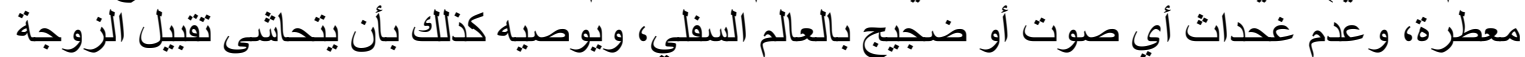

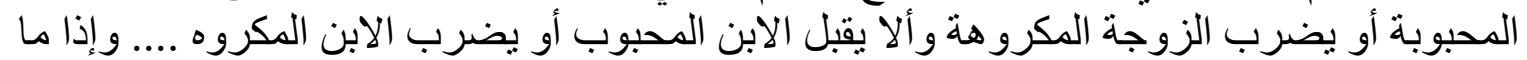
خالف هذه التعليمات يحذره جلجامش، بان العالم السفلي سيقبض عليه، وملكة العالم السفلي تسلط عليه

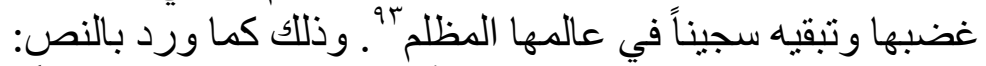
(أجاب) جلجامش إنكبيو (محنرآ):

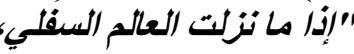

(عليك اتباع) تعليماتي!

(لا ترتلد) ألبسة نظيفة

لكي لا تعر(ف) بأثك غريب (عن المكان)؛

لا تمتسح بلهون معطرة

لأن الرائحة التي تنشرها

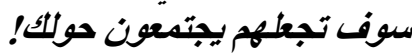

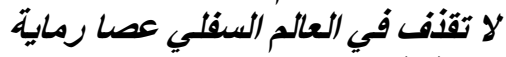

فالنين تصييهم يحبطون بك الكال

لا تشهر هراوة بيايك تكن

فبذلك ترعب الأثباح

لا تنتعل حذاءً:

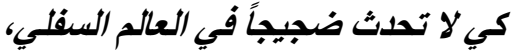

لا تقبل زوجتك المحبوية (إن التقيتها)

لا تضرب قل زوجتك المدقوتة (إن إلتقيتها)

لا تقبل ولد المحبوب،

لا تضرب قط ولدك المدقوت، العبون

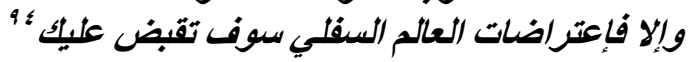

وكلمة إعتر اضات هنا هي ترجمة حرفية وتكون لمخالفة أنظمة العالم السفلي. 
كان سكان بلاد ما بين النهرين يؤمنون باستمر ار الحياة بعد الموت.

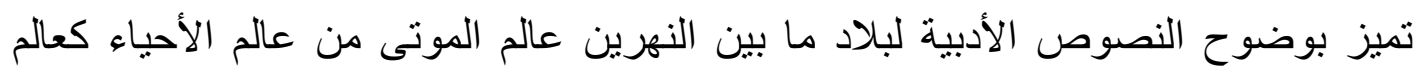
منفصل تماما.

كان فكر سكان بلاد ما بين النهرين حول الموتى والعالم السفلي سلبي وكئيب. وقد وُصف

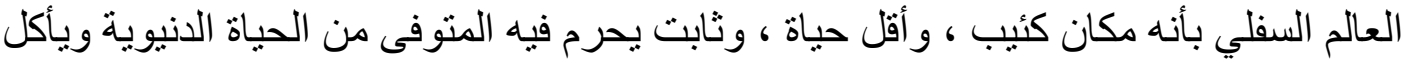

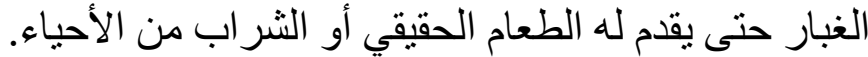
وقد وُصف الموتى في العالم السفلي بأنهم كائنات طموحة غير قادرة التئ على فعل أي شيء ، وحدد وضعهم بأفعالهم الدنيوية. مقارنة مفاهيم العالم السفلي في مصر بتلك الموجودة في بلاد ما بين النهرين ، كان العان العالم السفلي في مصر هو الطريق إلى حياة أبدية جديدة في حين أن العالم السفلي في بلاد ما ما بين

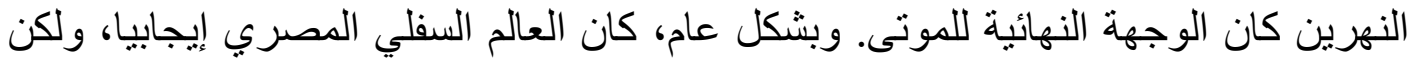

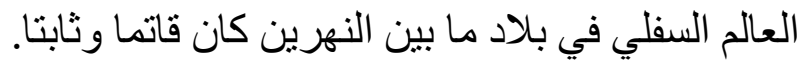
وفيما يتصل بموقع العالم السفلي، فقد وجد مفهومان رئيسيان: التصور الأفيني والتصني التصور الر أسي أو الإدراك الأفقي والإدر الك الر أسي. كان التصور الأفي الفقي يعتبر مكان العالم السفلي في الغرب ، بينما كان التصور الرأسي يعتبره تحت الأرض والألبسو الأبور (أي محيط المياه)، ويحيط بالعالم كله نُمو الكيان الهيلولي. تتفق الباحثة مع التصور الر أسي للموقع العالم السفلي كما اوضحت سبب الميل من خلا المصادر النصبة الأدبية. كذلك بالنسبة لموقع العالم السفلي لم يحدد بدقة ولكنة كان في مكان بعيد أو الجهة المقابلة للسماء (العالم المضئ). للعالم الأسفل العديد من المداخل كالقبر والجبل،..... بخلاف السبع بو ابات التي يقف على كل منها حارس. تم الربط بين الجبل والعالم السفلي من خلال مناظر بعض المعبودات على الأختام وكأنها

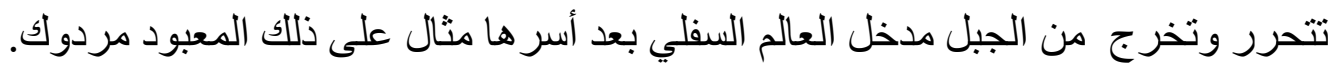
للعالم السفلي العديد من المسميات ولكن الأسم الأقرب لمعنى العالم السفلي كان "أر الي" حيث الترجمة الحرفية لهذا المسمى العالم السفلي. وبالنسبة لنظام العالم السفلي فيوجد مايشبه المحاكمة وتتر أس هذه المحكة المعبودة إيرشيكجال

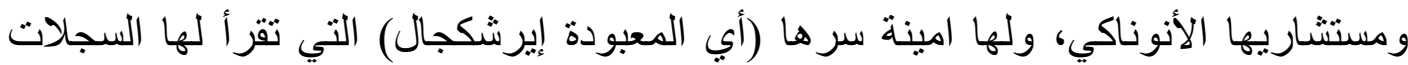

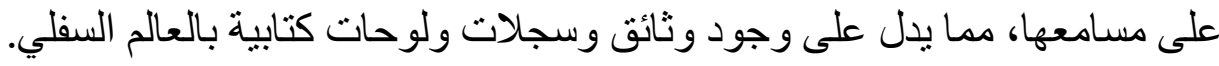
لاخول العالم السفلي لابد من الألتزام بقوانينه مثل عدم ارتداء ملابس نظيفة، وتئهدم إصدار

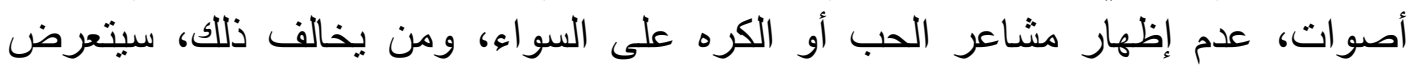
للمحاكمة من قبل رئيسة المحكمة ومستشار مئشاريها. 


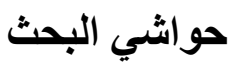

1-Inanna's descent to the netherworld is earlier Sumerian version. Ishtar's descent to the netherworldis later version of Akkadian, which is shorter and modified the earlier version. Inanna's (Ishtar's) seven stages to the underworld represent the process of death. These two myths have some connection with the agriculturalcycle of seasons as the myth "Baal cycle" does. This concept, the agricultural cycle of seasons, is more obvious in the Akkadian version (John Kampen, "Descent to the underworld", ABD Journal, Vol 2, New York, 2015, 145)

2-Inanna's descent to the netherworld is earlier Sumerian version. Ishtar's descent to the netherworldis later version of Akkadian, which is shorter and modified the earlier version. Inanna's (Ishtar's) seven stages to the underworld represent the process of death. These two myths have some connection with the agriculturalcycle of seasons as the myth "Baal cycle" does. This concept, the agricultural cycle of seasons, is more obvious in the Akkadian version (John Kampen, "Descent to the underworld", ABD Journal, Vol 2, New York, 2015, 145)

3 - From two myths, the Erra myth and the descent of Ishtar, the concept, the dead will become a kind of monster when they would return to the earth. The dead will lose their memories and will devour the living human. (The descent of Ishtar. V9-12); The myth Erra. I 175-178

4 - Katz, Dina, The Image of the Netherworld in the Sumerian Sources. Bethseda, Tel Aviv University,1993, 238; Innana (Ishtar) can be released because her lover Dumuzi (Tammuz) takes her place in the underworld (Philip Johnston, Shades of Sheol : Death and Afterlife in the Old Testament, DownersGrove: InterVarsity Press, 2002, 232

5 - John Kampen, "Descent to the underworld" ABD 2, 145

6 - John Kampen, "Descent to the underworld" ABD 2, 146.

7 - Hooke, S.H., Babylonian and Assyrian Religion, London, 1953, 206

8 - Katz, Image , 63.

9 - Although the underworld was for the dead, the master(s) of the underworld were the gods Ereskigal and Nergal

10 - J. F. Healey, "Death, Underworld and Afterlife in the Ugaritic Texts", Theses, University of London, 1977,70

11 - Katz, Image, I

12 - Drioton, Etienne, Religions of the Ancient East, New York, 1959, 114.

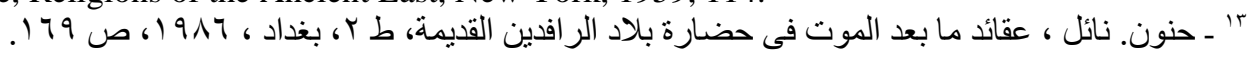

14 - Drioton, Etienne, Religions, 114

15 - Jastrow, M., Aspets of religious Belief and Practice in Babylonia and Assyria,New York, 1911, 408.

16 -Kunt Tallqvist, Sumerisch- Akkadische Namen der Totenwelt, Studia Orientalla, Vol.4, Leipzig, 1934, p.3.

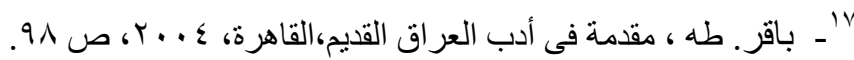

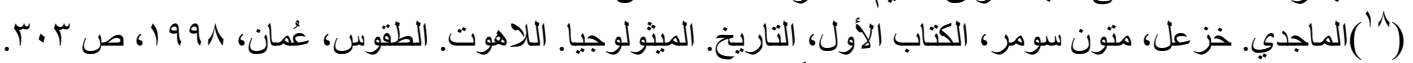

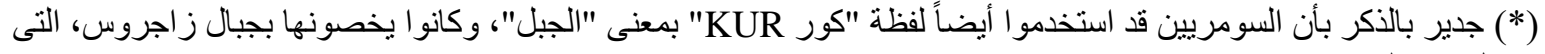

$$
\begin{aligned}
& \text { تفصل بلاد النهرين عن إيران: }
\end{aligned}
$$

Black, J. and Green, A., Black, J. and Green, A., Gods, Demons and Symbols of Ancient Mesopotamia, British Museum press, 1992, p. 114

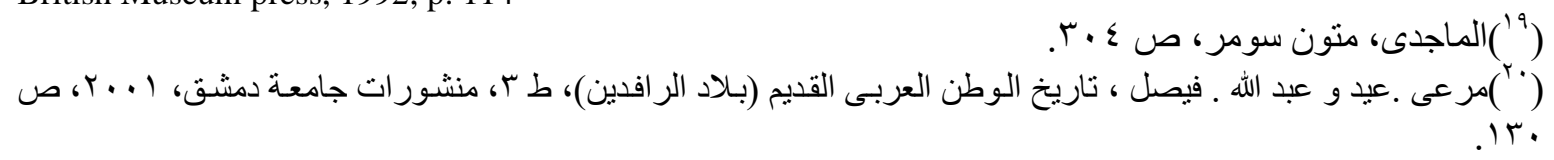

$\left({ }^{21}\right)$ Black, J. and Green, A., Gods, Demons and Symbols of Ancient Mesopotamia, p. 27.;

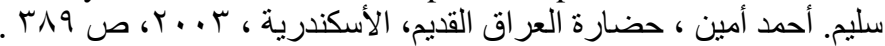

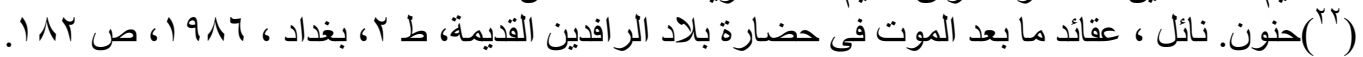

23 - John H. Walton, Ancient Near Eastern Thought and the Old Testament, Introducing theConceptual World of the Hebrew Bible (Grand Rapids, MI: Baker Academic, 2006), 318 ; Katz, Image, 54

24 - Walton, John H., Ancient Near Eastern Thought and the Old Testament: Introducing the Conceptual World of the Hebrew Bible. Grand Rapids, MI: Baker Academic, 2006, 318

25 - Katz, Image, 54

26- Doermann,Raph W., Sheol in the old Testament, Duke University, 1961, 118 


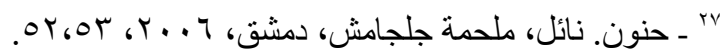

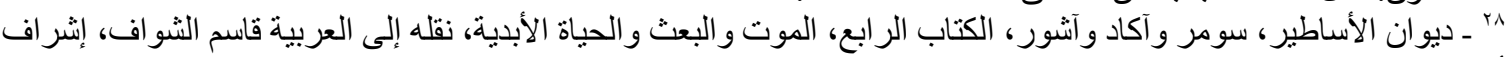

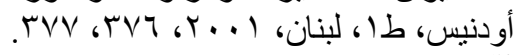

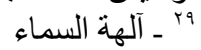

31- Katz, Image ,54

32 - Katz, Image , 238

33 - Heide, A., The Gilgamesh Epic and old Testament Paralles, Chicago, 1967, 170; Ebeling, E., in

Keilschrifttexte aus Assur Religiosen Inhalts. No.307, 34:73

34 - Hooke, S.H., Babylonian and Assyrian Religion, 219

35- Jacobsen, T., Taward the Image of Tamunuz and other Essays on Mesopotamian History and Culture, Ed.

William Moran, Chambridge, 1970, 363; Cuneiform Texts from Babylonian tablets in the British Museum,

London, 1890, $187-192$

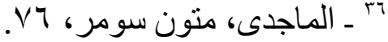

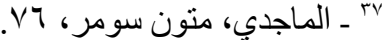

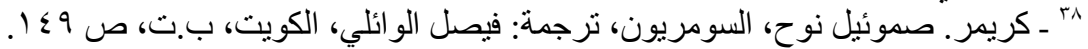

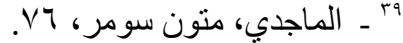

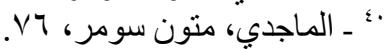

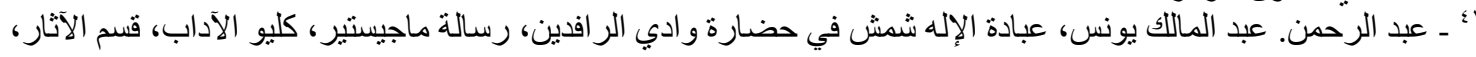

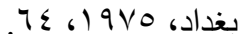

42 - Dally.S, Mythes from Mesopotamia, Oxford, 1989, 148.

44 - Dhorome, E. and Dussaud, R., Les Religions. Orietales, editor: Mona, Paris, 1949, 187.

45 - Kramer, S. N., The Sumerians, Chicago, 1963, 57.

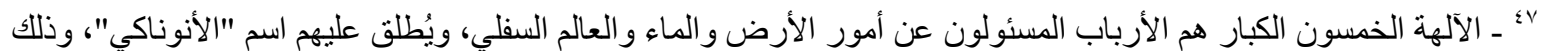

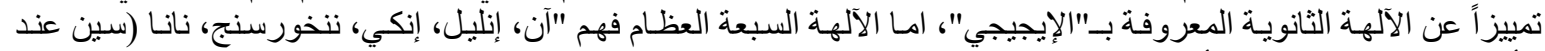

Kramer, S.N., the Sumerians, 122-123 .

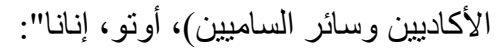

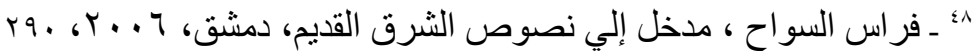

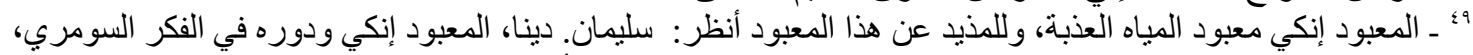

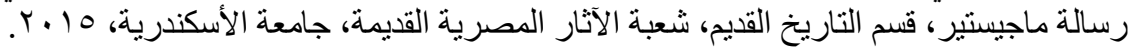

50 - Kunt Tallqvist, Sumerisch- Akkadische Namen der Totenwelt, $22 \mathrm{f}$

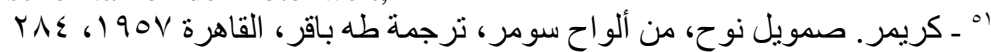

53 - Kramer, S. N., The Sumerians, 151

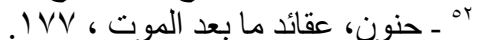

54 - Heinrich Zimmern, Zum Babylonischen Neujahrsfesh, II, Leipzig, 1918, $3 \mathrm{f}$

55 - Katz, Image , 238; Doermann, Sheol, 118

56 - Katz, Image , 238

57 - Routledge, "Death, " 30-32.

58 - Routledge, “Death, " 30-32.

59 - Katz, The Image of the Netherworld , 235; Jo A. Scurlock, "Death and the Afterlife in Ancient Mesopotamian Thought." CANE 3, 1888

60 - Paolo Xella, "Death and the Afterlife in Canaanite and Hebrew Thought." CANE 3, 2064.

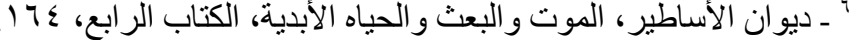

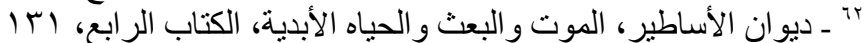

63 - Heimpel. W. ,"The Sun at Night and the Doors of Heaven in Babylonian Texts," JCS 38, 1986, 133

${ }^{64}$ - Rachel S. Hallote, Death, Burial, and Afterlife in the Biblical World: How the Israelites and Their

Neighbors Treated the Dead (Chicago: Ivan R. Dee, 2001), 107, 109

65 - Heide, A., The Gilgamesh Epic and old Testament Paralles, p.157; Ebeling, E., Tod und Leben Nach den Vorstellungen der Babylonier, Berlin, 1931, pp.140- 141

${ }^{66}$ - Ebeling, E., Tod und Leben Nach den Vorstellungen der Babylonier, p.171

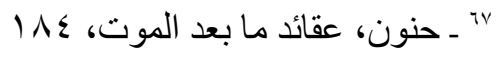


69 - CAD. Vol. 8; kigallu, p.349.

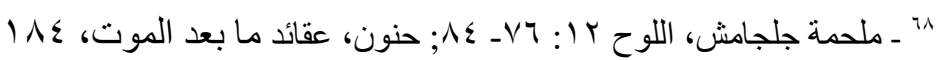

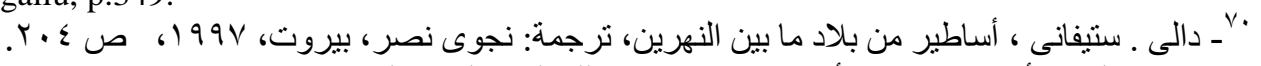

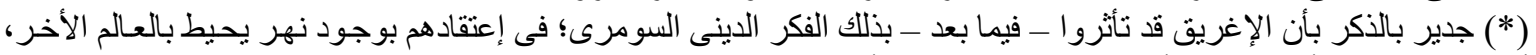

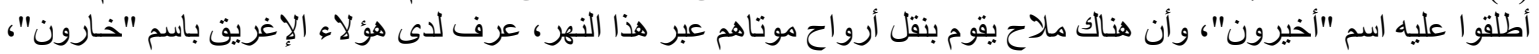

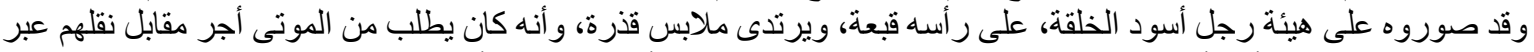

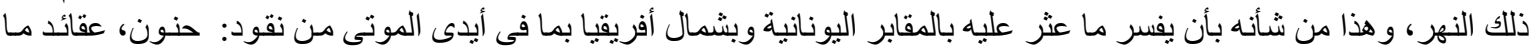

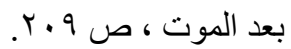

${ }^{71}$ Black, J. and Green, A., Gods, Demons and Symbols of Ancient Mesopotamia, p. 27.

${ }^{72-}$ Black, J. and Green, A., Gods, Demons and Symbols of Ancient Mesopotamia, p. 155. الجدير بالذكر أن الثهر العاثر من السنة الآشورية و المسمى تبت و الذي يتو افق مع شبط كان يسمى أحياناً شهر نهر

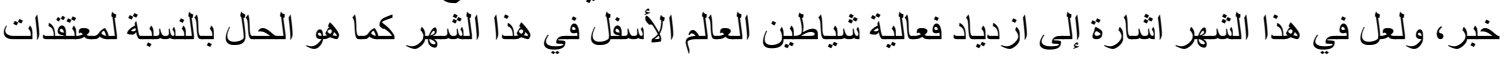

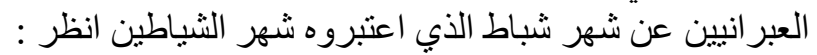

S. Langdon, Rabylonian Menologies and Semitic Calenders, p.38

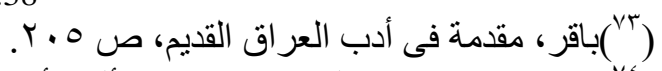

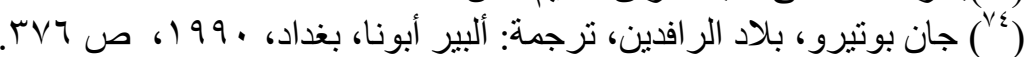

$\left({ }^{75}\right)$ Crawford, H., H.,Sumer and the Sumerians, Cambridge University Press,1992 , p. 119.; Gray , J., Near Eastern Mythology, London, 1982, p.8.

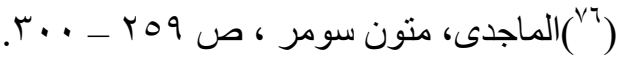

$\left({ }^{77}\right)$ Black, J. and Green, A., Gods, Demons and Symbols of Ancient Mesopotamia, p. 77.

$\left({ }^{78}\right)$ Westenholz,J.G.,"Goddesses of the Ancient Near East $3000-1000$ BC.", Ancient Goddesses, British Museum Press, 1998, p. 72.

$\left({ }^{79}\right)$ Kramer, S.N., Sumerian Mythology, New York, 1961 p. 91.

$\left({ }^{80}\right)$ Kramer, S.N., The Sumerians 2nd. ed., Chicago, 1964, p. 204.

$\left({ }^{81}\right)$ Black, J. and Green, A., Gods, Demons and Symbols of Ancient Mesopotamia, p. 180.

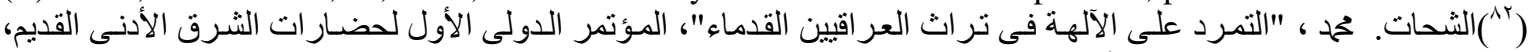

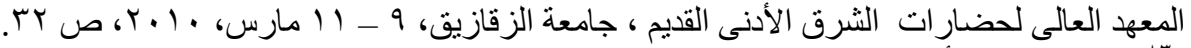

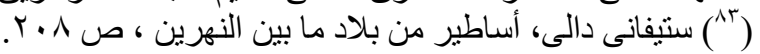

$\left({ }^{84}\right)$ Westenholz, J.G., "Goddesses of the Ancient Near East 3000 -1000 BC.", Ancient Goddesses, British Museum, 1998, p. 71.; Kramer, S.N., The Sumerians, p. 134.

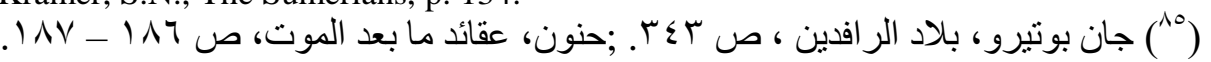

$\left({ }^{86}\right)$ Kubrt, A., The Ancient Near East, C.3000-330 BC, Vol.I, London,1995, p. 59, Kramer, S.N., The Sumerians, p. 131.

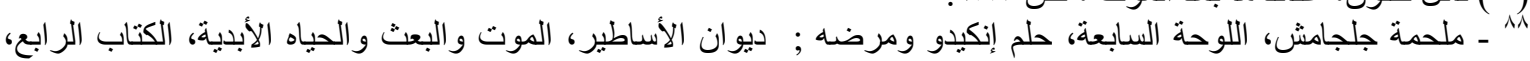
ודז- זדים

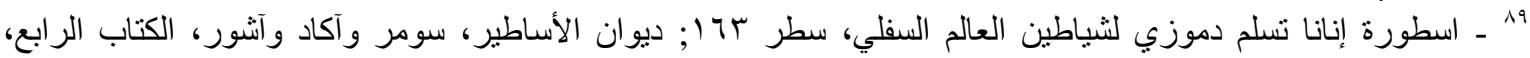
77 . . . I •" - اسطورة إيرشيكجال ونرجال، العدود الخامس، سطر · ’; ديوان الأساطير، الموت و البعث والحياه الأبدية، الكتاب الرابع، ص ع 17

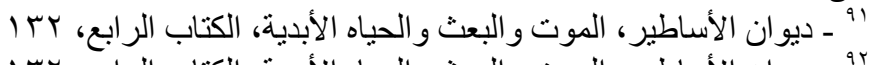

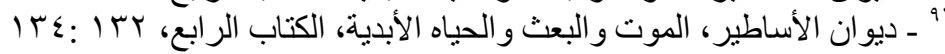

93 - Morris Fastorow, aspect of religious celled and practice in Babyionia ans Assyria, London, 1911, 320

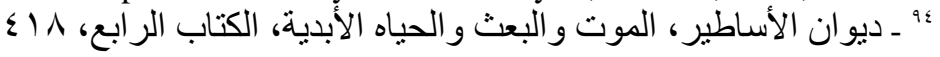

95 - King, L. W, Babylonian Religon and Mythology, London, 1899, 443 